\title{
Broodstock management and hormonal manipulations of fish reproduction
}

2

4 Constantinos C. Mylonas ${ }^{1}$, Alexis Fostier ${ }^{2}$ and Silvia Zanuy ${ }^{3}$

6

${ }^{1}$ Institute of Aquaculture, Hellenic Center for Marine Research, P.O. Box 2214, Heraklion,

$8 \quad$ Crete 71003, GREECE (mylonas@ @er.hcmr.gr)

${ }^{2}$ Institut National de la Recherche Agronomique (INRA), Unité de Recherche 1037 (UR1037),

10 SCRIBE, IFR140, 3500 Rennes, FRANCE (alexis.fostier@ rennes.inra.fr)

${ }^{3}$ Instituto de Acuicultura de Torre de la Sal (CSIC), Torre de la Sal s/n, Ribera de Cabanes, 
Mylonas, Fostier and Zanuy

TABLE OF CONTENTS

ABSTRACT .3

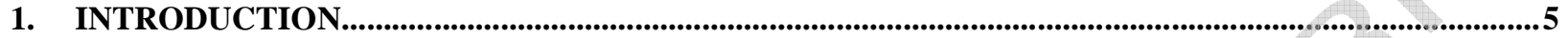

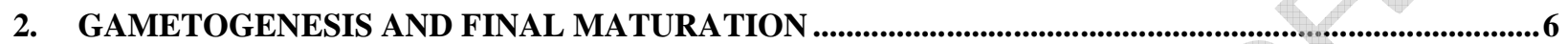

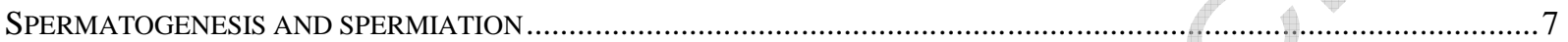

VITELLOGENESIS AND OOCYTE MATURATION (OM)

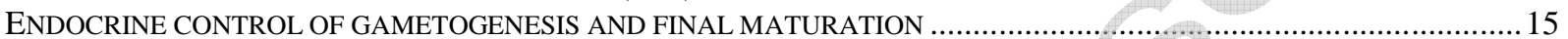

3. OPTIMAL CONDITIONS FOR REPRODUCTION IN CAPTIVITY ..................................................19

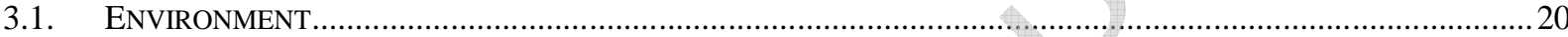

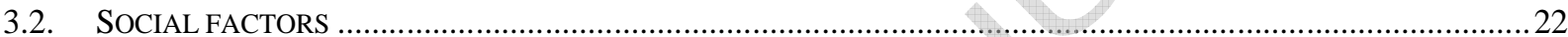

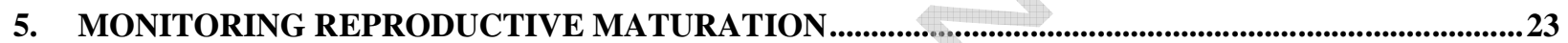

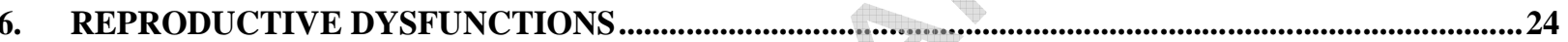

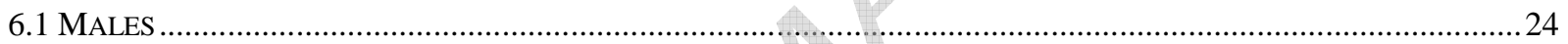

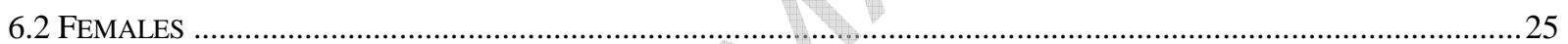

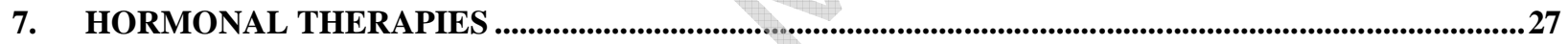

$34 \quad 7.1$ SPERMATOGENESIS AND SPERMIATION …

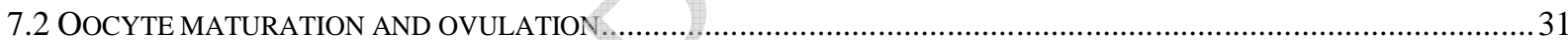

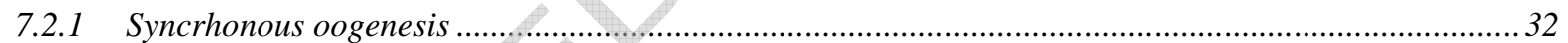

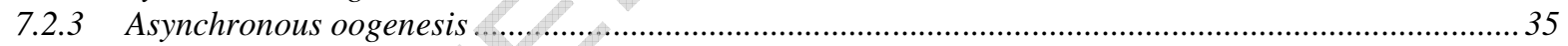

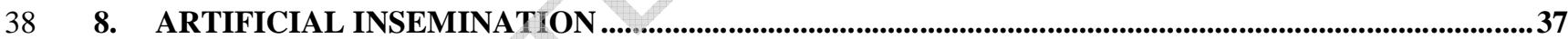

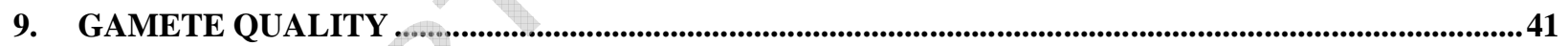

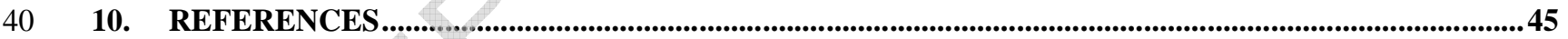

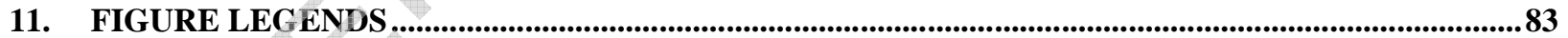




\section{Broodstock management and hormonal manipulations of fish reproduction}

\section{ABSTRACT}

Control of reproductive function in captivity is essential for the sustainability of commercial aquaculture production, and in many fishes it can be achieved by manipulating photoperiod, water temperature or spawning substrate. The fish reproductive cycle is separated in the growth (gametogenesis) and maturation phase (oocyte maturation and spermiation), both controlled by the reproductive hormones of the brain, pituitary and gonad. Although the growth phase of reproductive development is concluded in captivity in most fishes --the major exemption being the freshwater eel (Anguilla spp), oocyte maturation (OM) and ovulation in females, and spermiation in males may require exogenous hormonal therapies. In some fishes, these hormonal manipulations are used only as a management tool to enhance the efficiency of egg production and facilitate hatchery operations, but in others exogenous hormones are the only way to produce fertilized eggs reliably. Hormonal manipulations of reproductive function in cultured fishes have focused on the use of either exogenous luteinizing hormone (LH) preparations that act directly at the level of the gonad, or synthetic agonists of gonadotropin releasing hormone (GnRHa) that act at the level of the pituitary to induce release of the endogenous LH stores, which, in turn act at the level of the gonad to induce steroidogenesis and the process of $\mathrm{OM}$ and spermiation. After hormonal induction of maturation, broodstock should spawn spontaneously in their rearing enclosures, however, the natural breeding behaviour followed by spontaneous spawning may be lost in aquaculture conditions. Therefore, for many species it is also necessary to employ artificial gamete collection and fertilization. Finallly, a common question in regards to hormonal therapies is their effect on gamete quality, compared to naturally maturing or spawning broodfish. The main factors that may have significant consequences on gamete quality --mainly on eggs-- and should be considered when choosing a spawning induction procedure include (a) the developmental stage of the gonads at the time the 


\section{Mylonas, Fostier and Zanuy}

hormonal therapy is applied, (b) the type of hormonal therapy, (c) the possible stress induced by

70 the manipulation necessary for the hormone administration, and (d) in the case of artificial insemination, the latency period between hormonal stimulation and stripping for in vitro 72 fertilization.

Keywords: broodstock management, induced spawning, oocyte maturation, spermiation 


\section{Broodstock management and hormonal manipulations of fish reproduction}

\section{INTRODUCTION}

The number of aquatic species currently under domestication efforts is rising rapidly, due to the development of commercial aquaculture (Duarte et al., 2007). One of the prerequisites for domestication and the establishment of a sustainable aquaculture industry is the capacity to control reproductive processes of fish in captivity, and to acquire high quality seed (i.e., eggs and sperm) for grow-out of the marketable product. Although many cultured fishes today fulfil this condition, there are important species whose aquaculture industries depend almost exclusively on the collection of juveniles or adults from the wild. Such species include the very popular freshwater eel (Anguilla spp.), the Japanese yellowtail and greater amberjack (Seriola spp.), some groupers (Epinephelus spp.) and the bluefin tuna (Thunnus spp.) (Ottolenghi et al., 2004).

Reproduction of fish in captivity can be controlled by environmental manipulations, such as photoperiod, water temperature or spawning substrate. However, the ecobiology of some fishes is not well known, or it is impractical or even impossible to simulate the required environmental parameters for natural reproductive performance (i.e. spawning migration, depth, riverine hydraulics, etc.). In these instances, use of exogenous hormones is an effective way to induce reproductive maturation and produce fertilized eggs. Furthermore, in all cultured fishes, hormonal manipulations may be used as management tools to enhance the efficiency of egg production, increase spermiation and facilitate hatchery operations. Finally, hormonal therapies may be employed to induce gamete maturation and enable artificial collection in order to implement inter-specific hybridization, chromosome set manipulation or artificial fertilization for genetic selection programmes. 


\section{Mylonas, Fostier and Zanuy}

Broodstock management involves all the appropriate measures taken by the aquaculturist to enable a captive group of fish to undergo reproductive maturation and spawning, and produce fertilized eggs. As indicated above, this management may involve only manipulation of environmental conditions or it may include the use of exogenous hormones. The type of hormones, administration protocols and gamete acquisition procedures may vary depending on the reproductive biology of each cultured species, and a thorough understanding of the endocrine control of gametogenesis, final maturation and spawning is essential for the appropriate management of the species (See other manuscripts in this special issue).

\section{GAMETOGENESIS AND FINAL MATURATION}

Similar to other vertebrates, the reproductive cycle of fish is separated into two major phases (Fig. 1). The proliferation, growth and differentiation of the gametes constitute the first phase (spermatogenesis and vitellogenesis), while the maturation and preparation of the oocytes and spermatozoa for release and insemination constitutes the second phase (spermiation and oocyte maturation). With very few exceptions --notably the European eel (Anguilla anguilla) (van Ginneken and Maes, 2005), spermatogenesis and vitellogenesis usually take place in cultured fishes without significant problems, when optimal rearing conditions have been applied (Buchet et al., 2008; Okumura et al., 2003). The most common reproductive dysfunction in males is reduced sperm volume and diminished quality, whereas unpredictable occurrence or failure of oocyte maturation (OM), and hence ovulation or spawning (Mylonas et al., 2004a; Mylonas et al., 2004c; Mylonas and Zohar, 2001a), is commonly observed in females (Berlinsky et al., 1997; Billard, 1989; Vermeirssen et al., 1998; Vermeirssen et al., 2000). Therefore, hormonal therapies usually address problems related to diminished sperm production during the spawning season and the failure of OM in cultured fishes. 


\section{Broodstock management and hormonal manipulations of fish reproduction}

\section{Spermatogenesis and spermiation}

The gametogenic process in the males is separated into two phases (Fig. 1). Spermatogenesis is the first phase and it includes the proliferation of the spermatogonia, the multiplication of the spermatocytes I with multiple mitotic divisions, the production of spermatocytes II with meiotic division and their differentiation to spermatids (Fig. 2). The process is completed with the production of flagellated spermatozoa, i.e. spermiogenesis (reviewed by Billard, 1986; Schulz and Miura, 2002; Vizziano et al., 2008). The spermatoza are released in the sperm ducts during the second phase of the male reproductive cycle, i.e. spermiation, which occurs during the spawning season. Sperm is ejaculated spontaneously by the fish and with the exception of catfishes (Mansour et al., 2004; Viveiros et al., 2002), it can also be expressed easily from the testes after application of gentle abdominal pressure (i.e., stripping). Spermiation and ejaculation can be synchronized with female spawning via pheromonal communications (Stacey, 2003).

Spermatogenesis may be continuous in species showing a tubular testis type or discontinuous in species showing a lobular testis type, which is the most frequent among teleostean fish (Billard, 1986; Schulz and Miura, 2002; Vizziano et al., 2008). Also, spermatogenesis and spermiation may be temporally separated and during the spawning season the testes may contain exclusively spermatozoa (Billard, 1986; Malison et al., 1994). In most species, however, there is significant overlap between the two processes, with both spermatogenesis and spermiation taking place during the spawning season (Jackson and Sullivan, 1995; Mylonas et al., 2003a; Rainis et al., 2003), and it has been shown in the gilthead sea bream (Sparus aurata) that the spermatogonia and Sertoli cell proliferation activity is not 


\section{Mylonas, Fostier and Zanuy}

146

blocked by the presence of spermatozoa (Chaves-Pozo et al., 2005), in contrast to fish with synchronous spermatogenesis.

Usually, males show a longer period of spermiation, which encompasses the spawning season of females by a few months, and they can fertilize eggs of several females in the wild. In addition, a female may spawn with more than one male, either by spawning with many males on one occasion or by spawning with different males on successive occasions (Petersson and Järvi, 2001). These male and female behaviors secure the reproductive success of an individual and favor the maintenance of genetic variability within a wild population. The same process could be tentatively achieved in fish farms by in vitro fertilization of stripped eggs with a pool of sperm obtained from different males or by having several males and/or females in the same tank, when natural reproduction is possible. The latter is the chosen broodstock management method.

As mentioned above, spermatogenesis is completed with the process of spermiogenesis, an important step for the differentiation of the haploid spermatids into flagellated spermatozoa and during which the morphology of the species-specific spermatozoon is determined (Billard et al., 1986; Pudney, 1995; Schulz and Miura, 2002; Vizziano et al., 2008). In mammals, spermiation is known as a complex process by which elongated spermatids undergo their final maturation and are released from supporting Sertoli cells into the tubule lumen, which is open at both ends (Beardsley and O'Donnell, 2003). This process has been described at the morphological level, but its control remains poorly understood, although it is known that it requires the actions of both gonadotropins (follicle stimulating hormone, FSH and luteinizing hormone, LH), as well as intratesticular testosterone (T) (Saito et al., 2000). In fish, spermiation corresponds to the release of the spermatozoa from the spermatocysts into the sperm ducts. At the same time production of seminal fluid is observed (LaFleur and Thomas, 1991). At least in some species, this process may be associated with the acquisition of fertilizing capacity of the spermatozoa, 


\section{Broodstock management and hormonal manipulations of fish reproduction}

170

(i.e., capacitation) within the sperm ducts (Schulz and Miura, 2002). In viviparous fish species, spermatozoa may be packed in spermatozeugma or spermatophores, which can be formed within the spermatocysts or in the sperm ducts. In the latter case the spermatozeugmata are released during spermiation into the ducts and transported unmodified to the copulatory organ (Fishelson et al., 2007). Similar to mammals, there is a close morphological and functional intercellular communication between Sertoli cells and germ cells during fish spermatogenesis (De Montgolfier et al., 2007; Loir et al., 1995). At the end of the male fish reproductive cycle, junctions formed by spermatids with Sertoli cells are weak, but finger-like projections may be observed between spermatozoa present in the tubule lumen of rainbow trout (Oncorhynchus mykiss) testis (Loir et al., 1995), although in some fishes spermiation is associated with the degeneration of at least some of the Sertoli cells (Schulz et al., 2005b).

From a morphological standpoint, fish spermiation is characterized by the rupture of the spermatocysts and release of the spermatozoa in the sperm ducts. This is followed by the production of seminal fluid, causing 'hydration' of the testes (Schulz and Miura, 2002). In some species, especially the Siluriform catfishes, seminal vesicle secretions contribute to the seminal fluid and participate in prolongation and stabilization of sperm viability (Chowdhury and Joy, 2007). During spermiation, the produced milt (i.e., seminal fluid containing suspended spermatozoa) may be collected by stripping. In most cases, hydration of the milt is enough to allow the spermatozoa to be stripped and usable for fertilization (Vermeirssen et al., 2000). However, as mentioned earlier, in some fishes stripping of semen is difficult because of anatomical reasons (Viveiros et al., 2001).

Therefore, most spermiation induction methods employed in aquaculture are not designed to induce spermatogenesis, which is a long process lasting many days or weeks, but mainly to induce spermiogenesis and production of seminal fluid which allows a greater number of the 


\section{Mylonas, Fostier and Zanuy}

spermatozoa released from the spermatocysts to be "washed out" of the testes (Mylonas et al., 1997b; Mylonas et al., 1998a). Methods to induce spermiation are required in some situations when this process is blocked completely. This could be the case for poorly domesticated fish or when farming conditions are not appropriate with a species ecobiology. Spermiation control may be also needed in order to synchronize the production of sperm with female ovulation, for a good management of spawners. Finally, sperm needs to be available at the right time and with the required quantity and quality when either large breeding plans are managed for genetic selection purposes or to cryopreserve enough quantity of sperm, in order to preserve interesting genetic resources.

\section{Vitellogenesis and oocyte maturation (OM)}

For the purpose of hormonal manipulations for the induction of OM, ovulation and spawning, fish are separated into two classifications: fish that spawn only once during the reproductive season (synchronous and single-batch group-synchronous) and those who spawn multiple times (multiple-batch group-synchronous and asynchronous) (Tyler and Sumpter, 1996). Synchronous ovarian development is characteristic of semelparous fishes such as the Pacific salmons (Oncorhynchus spp) and freshwater eels, which reproduce only once in their lifetime. Single-batch group-synchronous fishes (Fig. 3A) reproduce only once during every annual reproductive period. Multiple spawning fishes, as the term implies, produce multiple spawns during every reproductive period (Fig. 3B). These spawns may be numerous and regular, e.g. daily or every other day for a period of 3-4 months (Mylonas et al., 2004b; Papadaki et al., 2008; Zohar et al., 1995); or can be few and irregular in their timing, e.g. 3-7 spawns with an inter-spawn period of between 3-10 days (Carrillo et al., 1995; Forniés et al., 2001; Marino et 


\section{Broodstock management and hormonal manipulations of fish reproduction}

al., 2003). Egg batch fecundity and egg size may decline with subsequent spawning events (Kjesbu et al., 1996; Mugnier et al., 2000; Mylonas et al., 2003b).

The type of strategy employed for oogenesis by different fishes has important implications in their broodstock management in aquaculture. For example, for synchronous fishes that spawn once in their lifetime (e.g., freshwater eels and Pacific salmons), sacrificing the fish and collecting their artificially matured gametes directly from the broodfish is a very effective and efficient method for producing fertilized eggs. Obviously the same approach could not be used for fish that reach reproductive maturation at a late age and are expected to have a long reproductive life (e.g., tunas, amberjacks or groupers). Similarly, stripping of eggs and artificial insemination may be used in annually spawning synchronous females to obtain the total amount of available eggs from each female, but the same may not be achieved with multiple spawning fishes that mature and ovulate only a small fraction of their total annual fecundity at every spawning event. Also, annually spawning synchronous fishes have a much more confined reproductive season (e.g., a few weeks) and the production of eggs over an extended period of time to cover grow-out production needs, requires the establishment of many stocks exposed to different photothermal manipulations in order to shift the spawning period (Bromage et al., 2001). Whereas two or three stocks of photoperiodically manipulated gilthead sea bream will be adequate to provide a hatchery with eggs for 9-12 months a year (Zohar and Mylonas, 2001b), for a similar production, six to eight stocks of European sea bass (Dicentrarchus labrax) must be maintained, resulting in a higher facility and management cost (Carrillo et al., 1993). Finally, the choice of hormonal therapy for the induction of maturation (mainly $\mathrm{OM}$ in the females) may also depend on whether the fish is a synchronous or asynchronous spawner (see later section).

The presence of large amounts of yolk in the fish egg is an efficient way of making available the necessary components to sustain the developing embryo and pre-larvae until the 


\section{Mylonas, Fostier and Zanuy}

opening of the mouth and exogenous feeding. Therefore, the sequestration of yolk precursors into the oocyte during oogenesis (i.e., vitellogenesis) is a key process for successful reproduction and the production of healthy progeny in aquaculture. Vitellogenesis is accompanied by an important growth of the oocyte due to the uptake of yolk precursor proteins, mostly vitellogenin (Vtg) and putatively very low-density lipoproteins (Babin et al., 2007). Vitellogenin, a bulky and complex calcium-binding phospho-glycoprotein synthesized by the liver, is selectively sequestered by the growing ovarian follicles via specific receptors (VtgRs) clustered in endocytic clathrin-coated pits giving rise to the formation of Vtg-containing coated vesicles that move into the peripheral oolema (Hiramatsu et al., 2006). Vesicles fuse with lysosomes leading to the formation of the multivesicular bodies (MVB), which increase in size and are gradually transformed into yolk granules and then into large yolk globules (Le Menn et al., 2007).

Besides, MVBs contain lisosomal enzymes, such as Cathepsin D that cleave Vtg into the yolk polypeptides. The participation of this protease and, to some extent, Cathepsin B in Vtg processing has been shown both in freshwater and marine fish (see review by Cerdá et al., 2007).

As in other vertebrates, beginning at the $\mathrm{N}$ terminus, the precursor of a complete teleost Vtg molecule consists of a signal peptide, a lipovitellin heavy chain ( $\mathrm{LvH})$, a phosvitin $(\mathrm{Pv}), \mathrm{a}$ lipovitellin light chain (LvL) and a von Willebrand factor type D domain (Vwfd) that in teleosts is cleaved into a $\beta^{\prime}$-component $\left(\beta^{\prime}\right.$-c) and $\mathrm{C}$-terminal coding region $\left[\mathrm{NH}_{2}-\left(\mathrm{LvH}-\mathrm{Pv}-\mathrm{LvL}-\beta^{\prime}-\mathrm{CT}\right)\right.$ $\left.\mathrm{COO}^{-}\right]$. Once assembled, Vtg is glycosylated and phosphorylated post-translationally, and secreted as dimmers to the plasma (Finn, 2007). The presence of multiple Vtg genes has been confirmed in various teleosts (Finn, 2007; Hiramatsu et al., 2006; Sawaguchi et al., 2006) and the existence of a noticeably large number of complete Vtg genes was verified in rainbow trout and zebrafish (Danio rerio). In the former, the identity of the genes encoding Vtg was very high and, thus, the translated products were possibly very similar (see Hiramatsu et al., 2002 for 


\section{Broodstock management and hormonal manipulations of fish reproduction}

references). Nevertheless, a novel Vtg characterized by a missing phosvitine domain was shown to be present among the zebrafish Vtg genes. This novel "incomplete" Vtg was designated as phosvitin-less form (PvlVtg; $\mathrm{NH}_{2}$-LvH-LvL-COOH) and was also identified in two tilapia species. Recently, three forms of vitellogenin, VtgA, VtgB and VtgC (PvlVtg) have been identified in many fishes (see Amano et al., 2008; Hiramatsu et al., 2006; Sawaguchi et al., 2006). In general, it appears that members of higher teleost taxa (Paracanthopterigii and Acanthopterigii spp) express both VtgA and VtgB; additionally VtgC seems to be widely represented among teleosts (Matsubara et al., 2003).

As in other oviparous vertebrates, in teleosts the enzymatic cleavage of Vtg gives rise to the typical suit of yolk proteins that include the lipovitellin ( $\mathrm{Lv})$, the phosvitin $(\mathrm{Pv})$ and the $\beta$ '-c. The Lv is a highly lipidated yolk protein consisting of two polypeptides, the Lv heavy-chain $(\mathrm{LvH})$ and the $\mathrm{Lv}$ light chain $(\mathrm{LvL})$. The $\mathrm{Pv}$ is a smaller protein in which more than half of its amino acid residues are contained in highly phosphorylated polyserine domains that confer Vtg its calcium-binding properties. The $\beta$ '-c is the third yolk protein that usually contains neither lipid nor phosphorus (Hiramatsu et al., 2006; Hiramatsu et al., 2002). Lipovitellin appears to serve mainly as nutritional source of amino acids and lipids to the developing embryo, whereas $\mathrm{Pv}$ provides the necessary minerals required for its skeletal and metabolic functions. Until now, no physiological or nutritive functions have been attributed to the $\beta$ '-c or C-terminal peptide (Hiramatsu et al., 2006).

At the end of vitellogenesis, when the accumulation of the necessary yolk proteins and mRNAs for embryonic development has been completed, hormonal stimulation allows the oocytes to undergo OM. After oocyte maturation, ovulation takes place and meiosis is reactivated and completed upon fertilization (Kinsey et al., 2007). During OM, drastic morphological changes are observed in the oocyte together with progression of meiosis. The 


\section{Mylonas, Fostier and Zanuy}

most noticeable features, depending on the species, are lipid droplet coalescence and yolk globule coalescence which result in the clarification of the oocyte's cytoplasm, migration of the nucleus (germinal vesicle, GV) to the periphery of the oocyte and dissolution of the nucleus membrane (GV breakdown, GVBD), and a dramatic increase in volume due to water uptake (Cerdá et al., 2007). The GV is visible under the microscope after some chemical processing, and disappears when GVBD takes place.

In addition to the initial processing of Vtg upon sequestration into the growing oocyte, which is achieved mainly by Cathepsin $\mathrm{D}$, a second phase of much more intense proteolysis of the yolk proteins takes place during OM. The enzymes responsible for this second proteolysis have been identified in few species; Cathepsin L seems to be the responsible in gilthead sea bream, whereas Cathepsin B-like protease seems to be involved in barfin flounder (Verasper moseri) (reviewed by Hiramatsu et al., 2006). In addition to its obvious role in providing free aminoacids (FAAs) for the developing embryo and larva, the intense proteolysis of the Vtgderived yolk proteins is important also for the hydration of the oocyte (Cerdá et al., 2007 ). This is because the produced FAAs and other organic osmolytes play a very important role in increasing the osmotic pressure of the oocyte's cytoplasm, driving an aquaporin-mediated water uptake by the maturing oocyte. A limited hydration may also occur in freshwater fish possessing benthic eggs (Milla et al., 2006). However, this second proteolysis is particularly important in marine fish possessing pelagic eggs and exhibiting a noticeable hydration at OM (Matsubara et al., 1999). In these teleosts, $\mathrm{Vtg} \mathrm{A}$ and $\mathrm{VtgB}$, and their derivative yolk proteins are thought to play distinct roles in regulating oocyte hydration (Finn, 2007; Finn et al., 2002; Sawaguchi et al., 2006). A dual Vtg system responsible of a specific physiological mechanism of egg buoyancy was firstly described in barfin flounder (Matsubara et al., 1999). During OM most VtgA-derived yolk proteins are cleaved into FAAs but the heavy chain of Lv derived from 


\section{Broodstock management and hormonal manipulations of fish reproduction}

$\mathrm{VtgB}(\mathrm{LvHB})$ remains greatly intact. Thus, the ratio of $\mathrm{Vtg} A$ and $\mathrm{VtgB}$ accumulated during vitellogenesis regulates the yield of FAAs during OM, which generate a specific osmotic gradient responsible for oocyte hydration and regulation of egg buoyancy. The remaining LvHB serves as nutrient source for late embryo developmental stages (Matsubara et al., 1999). This seems to be a common situation among marine pelagophil fishes, which spawn pelagic eggs (Amano et al., 2008; Finn, 2007; Hiramatsu et al., 2006; Sawaguchi et al., 2006). Up to date, no molecular alteration of $\mathrm{VtgC}$ has been verified during $\mathrm{OM}$ in any teleost, thus it does not contribute to the OM-associated production of FAAs. Thus the importance of Vtg multiplicity is obvious because of its participation in critically important physiological reproductive events of marine teleosts, including hydration of mature oocytes, buoyancy and generation of the necessary nutrient stocks for embryo and larvae (Amano et al., 2008).

In conclusion, both vitellogenesis and $\mathrm{OM}$ are essential events of female reproductive physiology, in which the multiple Vtg scheme plays an important physiological role in the provision of the required nutrients for the embryo and larval development, as well as the accomplishment of proper egg buoyancy. Improperly hydrated eggs usually do not develop into viable larvae and those with inadequate yolk supplies give rise to very poor survival of the progeny (Brooks et al., 1997; Unuma et al., 2005). Thus, it is essential to undertake fundamental studies in aquacultured teleost species, since both processes have important implications in the quantity and the quality of offspring obtained for the intensive production of these species.

\section{Endocrine control of gametogenesis and final maturation} and $\mathrm{OM}$ ) are regulated by a cascade of hormones along the brain-pituitary-gonad (BPG) axis (Fig. 1). In this axis, the secretion of the pituitary gonadotropins FSH and LH is controlled by 


\section{Mylonas, Fostier and Zanuy}

the brain via the stimulatory action of the GnRHs (Peter and Yu, 1997; Yu et al., 1997), which are the primary neuropeptides regulating reproduction, acting as integrators of external information (e.g., environment, temperature, water fall and social interactions). Dopamine (DA) in some fishes exerts a negative effect on the functions of GnRH on the pituitary gonadotrophs (Chang and Jobin, 1994). The FSH and LH are released into the bloodstream to act on the gonad, where they stimulate the synthesis of the sex steroid hormones (androgens, estrogens and progestogens), which are the ultimate effectors of gonadal development.

Hormonal regulation of fish spermatogenesis and spermiation has been described previously (Billard et al., 1990; Schulz and Miura, 2002; Vizziano et al., 2008; Watanabe and Onitake, 2008) and an updated review can be found in this special issue (Schulz et al., 0000). Testicular spermatogenesis, as well as spermiation, is regulated by pituitary FSH and LH secretion through the action of the sex steroid hormones, as well as other growth factors. Before the onset of spermatogenesis, spermatogonial stem cell renewal seems to be regulated by $\mathrm{E}_{2}$ acting on Sertoli cells (Miura and Miura, 2003). The androgen 11 keto testosterone (11KT) is the major regulator of spermatogenesis, while the maturation inducing steroid (MIS) regulates sperm capaciation and spermiation (Miura and Miura, 2003). Both steroids are synthesized by the somatic Leydig cells of the testes, after GtH stimulation. The LH is mainly involved in the stimulation of androgen production in Leydig cells, whereas FSH seems to exert more complex functions in the male testes, stimulating androgen production from the Leydig cells, as well, but also regulating Sertoli cell activity during spermatogenesis. Although the regulatory mechanisms of FSH are mostly unknown, possible functions of FSH in the testes include the stimulation of Sertoli cell proliferation and differentiation, and the synthesis of certain growth factors that act as autocrine and paracrine factors involved in Sertoli cell proliferation and differentiation and germ cell development (Schulz and Miura, 2002). 


\section{Broodstock management and hormonal manipulations of fish reproduction}

The onset of spermatogenesis is marked by the switch from spermatogonial self-renewal

to spermatogonial proliferation through a number of mitotic divisions that is species specific in fishes, a process controlled by the secretion of pituitary GtHs (mainly FSH) (Schulz and Miura, 2002). The FSH acts on Sertoli cells and stimulates $11 \mathrm{KT}$ biosynthesis, which in turn regulates the full process of spermatogenesis, mediated also by growth factors (e.g., insulin-like growth factor I, IGF-I or activin B) secreted by the Sertoli cells. In males, FSH levels are high at early spermatogenesis, increase to maximum levels during the rapid testicular growth phase and then decline after spawning. On the other hand, LH is low during early spermatogenesis, increases during spermiation and peaks during the spawning season (Gomez et al., 1999; Mateos et al., 2003; Miwa et al., 1994; Mylonas et al., 1997c), when LH induces a shift in the steroiodogenic pathway of the testes leading to the production of the MIS. The MIS is synthesized in the spermatozoa by the activity of $20 \beta$-hydosysteroid dehydrogenase, converting $17 \alpha$ hydroxyprogesterone synthesized in Leydig cells (Asahina et al., 1990; Barry et al., 1990). In response to the production of MIS there is activation of specific enzymes that increase seminal plasma $\mathrm{pH}$, which in turn induces spermatozoa capacitation (Alavi and Cosson, 2005; Clearwater and Crim, 1998; Miura et al., 1992; Woolsey and Ingermann, 2003). In males, androgen production ( $\mathrm{T}$ and $11 \mathrm{KT}$ ) remains high through the entire spawning period, even while MIS levels are high, since spermatogenesis, spermiogenesis and spermiation occur concurrently.

In females, a predominant role has been suggested for FSH during vitellogenesis in fishes with synchronous ovarian development. On the other hand, in fish with asynchronous ovarian development the role of FSH in vitellogenesis is less clear and a possible function has been ascribed also to LH. This is due, partly, because of the parallel fluctuations of FSHß and LHß transcripts during ovarian growth of these species (see review by Rosenfeld et al., 2007) and partly because the gonadotropic control of vitellogenesis is relying on the follicular production 


\section{Mylonas, Fostier and Zanuy}

of $\mathrm{E}_{2}$ and it has been shown that both $\mathrm{FSH}$ and $\mathrm{LH}$ are able to stimulate its synthesis in vitro.

However, a differential regulation of the two gonadotropins could occur also at the receptor level. Thus, in the Atlantic halibut (Hippoglossus hippoglossus), which shows an asynchronous oogenesis, FSH receptors but not $\mathrm{LH}$ receptors were expressed in the smallest follicles corresponding to the stages of primary growth and vitellogenesis (Kobayashi et al., 2008). Also, it has been shown in the European sea bass, that homologous FSH stimulates the release of $\mathrm{E}_{2}$ by ovarian fragments in a dose- and time-dependent manner (Molés et al., 2008). In addition, this stimulation was greater in females in early and mid vitellogenesis, coinciding with the time of high expression levels of FSH receptor (FSHR) in the ovarian follicles (Luckenbach et al., 2008; Rocha et al., 2008). Also, a specific role of FSH on stimulating cytochrome P-450 aromatase activity and mRNA expression in vitro, the enzyme catalyzing the conversion of $\mathrm{T}$ to $\mathrm{E}_{2}$, has been demonstrated in brown trout (Salmo trutta) follicles from vitellogenic ovaries (Montserrat et al., 2004). Furthermore, FSH seems to stimulate Vtg incorporation into follicles of rainbow trout (Jalabert, 2005). Gonadotropic stimulation of the ovary during the period of vitellogenesis induces steroidogenesis in a two-cell biosynthetic process, in which the outer theca layer synthesizes $\mathrm{T}$ that is transported into the granulosa cells and converted to $\mathrm{E}_{2}$. During vitellogenesis, $\mathrm{E}_{2}$ regulates oocyte development and the synthesis of $\mathrm{Vtg}$ and other yolk related proteins by the liver. In addition to the gonadotropic and $\mathrm{E}_{2}$ control of vitellogenesis, it has been suggested that other hormones (e.g., T) and paracrine factors could cooperate in the Vtg uptake by the growing follicles (reviewed by Hiramatsu et al., 2006; Jalabert, 2005; Polzonetti-Magni et al., 2004).

At the conclusion of vitellogenesis, $\mathrm{OM}$ is triggered by the action of $\mathrm{LH}$ on the follicle cells, which synthesize and secrete the maturation inducing hormone (MIH) or maturation inducing steroid (MIS) (Nagahama et al., 1994; Suwa and Yamashita, 2007). In salmonids 


\section{Broodstock management and hormonal manipulations of fish reproduction}

(Onchorhynchus and Salmo spp.), and a few freshwater and marine fishes the MIS is the progestin 17,20ß-dihydroxy-4pregnen-3one (17,20ßP). In some other marine species, a derivative of $17,20 ß \mathrm{P}$ the $17 \alpha, 20 ß, 21$-trihydroxy-4-pregnen-3-one (20ßS) has been described to act as MIS (King et al., 1995; Schulz and Miura, 2002; Thomas et al., 1995). Both 17,20ßP and 20ßS are acting as MIH in European sea bass (Asturiano et al., 2000), striped bass (Morone saxatilis) (Mylonas et al., 1997c) and red seabream (Pagrus major) (see review by Suwa and Yamashita, 2007) (Fig. 4). The MIS binds to specific receptors on the oocyte plasma membrane and the signal received in the oocyte surface is transduced to the cytoplasm to finally result in the formation and activation of the maturation-promoting factor (MPF), which is responsible for the resumption of meiosis and completion of oocyte maturation (Nagahama et al., 1994). Although in some species both FSH and LH have been implicated in the process (Jalabert, 2005), it is generally admitted that oocyte maturation is a two stage LH-dependent event, with some paracrine factors also being involved (Bobe et al., 2008). The first stage is refered to as oocyte maturational competence (OMC) and consists on the acquisition by the follicles of the ability to produce and by the oocyte to respond to MIH (Patiño et al., 2001). The second stage comprises the period of actual production of MIH and resumption of oocyte meiosis (Patiño and Sullivan, 2002).

\section{OPTIMAL CONDITIONS FOR REPRODUCTION IN CAPTIVITY}

The first step in proper broodstock management is the identification of the optimal conditions required for a species to undergo reproductive maturation and produce gametes of good quality. The various factors involved during gametogenesis and having impact on gamete quality are examined elsewhere in this special issue (Bobe and Babiak 0000). This section 


\section{Mylonas, Fostier and Zanuy}

focuses on environmental factors that need to be controled in order to obtain normal spawning. Data on the eco-biology of each species of interest in its natural environment may be very useful in creating adequate culture conditions, leading to reproductive maturation and spawning.

Environmental factors may be used during gametogenesis to manipulate fish spawning time in order to get viable gametes on a year-round basis (Bromage et al., 2001; Chemineau et al., 2007). Such manipulations may affect reproductive performance (King and Pankhurst, 2007; Pankhurst and Thomas, 1998). In some cases, a proper control of environmental factors may be enough to obtain natural spawning from cultured fishes, as in the African catfish (Clarias gariepinus) (El Naggar et al., 2006; Okumura et al., 2003). Besides, employing optimal environmental conditions reduces stress, which may be enhanced by the spawning induction process itself (Mousa and Mousa, 2006).

\subsection{Environment}

Spawning induction efficiency may depend greatly on water temperature. Within the range of physiological temperatures, higher temperatures usually speed up the process without any adverse effects. Outside this range, higher temperature is unfavourable and may affect spawning success and progeny quality. Thus, in Arctic charr (Salvelinus alpinus), which spawns naturally at a very low temperature, a DA inhibition of LH release may occur at $10^{\circ} \mathrm{C}$ (Gillet et al., 1996). High temperature may also delay the ovarian response of rainbow trout to $\mathrm{GtH}$, by modifying its steroidogenic pattern (Pankhurst and Thomas, 1998). It is also known that temperature may modulate steroid conjugation and thus active free steroid concentration (Kime, 1979). On the contrary, in species spawning in warmer water, such as the black sea bass (Centropristes striata), low temperature may delay this response (Cerdá et al., 1996), and in common carp 


\section{Broodstock management and hormonal manipulations of fish reproduction}

negatively correlated with water temperature within the range of $20-26^{\circ} \mathrm{C}$ (Drori et al., 1994). However, a deleterious effect of too high temperature was observed in grass carp

(Ctenopharyngodon idella), by acting at various levels of the brain-pituitary-gonad endocrine axis (Glasser et al., 2004).

Salinity is another environmental parameter that can influence reproductive function.

Because freshwater is limiting and transferring large broodstock is costly and cumbersome, anadromous species such as salmons, which normally spawn in fresh water, are usually maintainted in seawater during the reproductive season. However, ovulation may be partially blocked in seawater and follicle hydration is disturbed (Sower and Shreck, 1982), a dysfunction that may be related to the loss of hypo-osmoregulatory ability in mature fish (Uchida et al., 1997). In such case, a short transfer to freshwater may be enough to overcome this blockage (Haffray et al., 1995). On the other hand, in many euryhaline species spawning induction can be successful at various salinities (Haddy and Pankhurst, 2000; Lee et al., 1992). Thus, in the black bream (Acanthopagrus bucheri), GnRHa treatment induced ovulation at salinities ranging from 5\%o to 35\% (Haddy and Pankhurst, 2000). However, a 17,20ß-dihydroxy-4-pregnen-3-one plasma level increase was detectable only at $20 \%$, and the number of ovulations and fertilization success were lowest in fish held at $5 \%$ o.

Tank size, water volume and/or depth and stocking density have been shown to influence reproductive success in some cultured fishes. Spontaneous spawning behaviour usually requires moderate to large holding volumes and low stocking densities in most fishes, including the greenback flounder (Rhombosa tapirina) (Pankhurst and Fitzgibbon, 2006). In the Nile tilapia

(Oreochromis niloticus), a low stocking density and water-flow rate is favourable for spontaneous spawning and good egg quality (Tsadik and Bart, 2007). However, the domestication process facilitates spontaneous spawning in captivity as stressed by Zohar and 


\section{Mylonas, Fostier and Zanuy}

Mylonas (2001a) for the gilthead seabream. Exept in species that require substrate for their spawning, optimizing tank size and water depth should be enough in most fishes to facilitate normal breeding behaviour and obtain successful spawning (Okumura et al., 2003; Okumura et al., 2002), although the impact of such factors may be more, or less significant depending on the species (Buchet et al., 2008; Ibarra-Castro and Dunca, 2007). Even a large pelagic species such as yellowfin tuna (Thunnus albacares) may spawn in a relatively small tank (Wexler et al., 2003). In fact, such factors are difficult to analyze by themselves, because tank size is correlated to water volume and depth, and may also influence water flow rate and quality (i.e., dissolved oxygen).

\subsection{Social factors}

Social interactions have major consequences on spontaneous spawning, both in male and female fish, and attention has been especially paid to pheromones (Stacey, 2003), with goldfish

(Carassius auratus) being a leading model of hormonal sex pheromone function (Appelt and Sorensen, 2007). However, applications of breeding behaviour and its pheromonal control to broodstock management remain limited (Hong et al., 2006).

In several practical trials for spawning induction, a male to female sex ratio equal or higher to 1 is preferred (Haddy and Pankhurst, 2000; Meseda and Samira, 2006; Pavlidis et al., 2004). In the spotted rose snapper, no significant difference was observed between male to female sexratios of $1: 1,1: 3$ or 1:5 (Ibarra-Castro and Dunca, 2007). Also, spawning may be more efficient in groups than in single pairs both, for spontaneous spawning (El Naggar et al., 2006) and after spawning induction (Forniés et al., 2003). However rigorous experiments evaluating properly the optimal sex ratio for cultured broodstocks are rarely published. 


\section{Broodstock management and hormonal manipulations of fish reproduction}

\section{MONITORING REPRODUCTIVE MATURATION}

Accurate evaluation of the stage of reproductive maturation is a prerequiste for the success of hormonal induction of OM and spermiation, so that the type of the necessary hormonal treatment can be determined and the time of adminstration chosen. Treatments given to immature individuals or to adult fish too early in the reproductive cycle are ineffective or inefficient. The most common, practical and perhaps reliable method of determining stage of reproductive maturation in fish is the aquisition of milt by gentle abdominal pressure (Fig. 5A) in the males, although in some species this is not possible (Viveiros et al., 2002), and the biopsying of developing oocytes from the ovary with the use of a catheter in the females (Fig. $5 B)$.

The stage of ovarian maturation is usually determined by (a) measuring the mean or maximum oocyte diameter (Garcia, 1989; Mylonas et al., 2004c; Shiraishi et al., 2005), (b) determining the position of the nucleus (germinal vesicle) (Billard et al., 1995b; Kagawa et al., 2005; Lutes et al., 1987; Mylonas et al., 1995b; Yaron, 1995) or (c) identifying the onset of coalescence of the lipid droplets (Fauvel et al., 1999; Mylonas et al., 2003b; Mylonas et al., 1997d). The stage of testicular maturation may not be evaluated using testicular biopsies during spermatogenesis, and is usually limited to the period of spermiation, when milt can be obtained using abdominal pressure (Billard et al., 1995a; Rurangwa et al., 2004). The stage of spermiation is evaluated based on the ease and/or amount of milt released after abdominal pressure, using subjective evaluation scales. For example, a spermiation index may be established on a subjective scale from 0 to 3 , with $0=$ no sperm released, $1=$ only a drop of sperm released after multiple stripping attempts, $2=$ sperm easily released after the first 


\section{Mylonas, Fostier and Zanuy}

\subsection{Males}

stripping attempt, and $3=$ copious amounts of sperm flowing with the slightest abdominal pressure (Mylonas et al., 2003a).

Other methods for evaluating stage of reproductive maturation include the determination of plasma levels of Vtg in females, or sex steroid hormones in both males and females, as these change dramatically and reliably during the different stages of gametogenesis and maturation. However, these methods are more invasive and may have a process time of hours to days, depending on the method of quantification. Recently, non-invasive methods have been developed for measuring female specific proteins or sex steroid hormones in skin mucus (Hiramatsu et al., 2006; Kishida et al., 1992; Schulz et al., 2005a). Such methods are better suited for large fish that are difficult to handle or very prone to stress, such as the bluefin tunas (Thunnus spp) (Corriero et al., 2007).

\section{REPRODUCTIVE DYSFUNCTIONS}

The reproductive dysfunctions observed in culture range from the complete absence of reproductive development observed in freshwater eel (Kagawa et al., 2005; Palstra et al., 2005; van Ginneken and Maes, 2005), to the absence of only gamete release (i.e., spawning) observed in cultured salmonids (Bromage et al., 1992). However, the most common dysfunctions include the production of lower quantity of milt and/or sperm during the spermiation period and the failure to undergo OM at the completion of vitellogenesis (Mañanos et al., 2008; Mylonas and Zohar, 2001b; Mylonas and Zohar, 2007; Zohar and Mylonas, 2001b).

\footnotetext{
As mentioned earlier, reproductive dysfunctions of captive fishes are not restricted to
} females, since males may produce a reduced amount of milt and of lower quality, even though 


\section{Broodstock management and hormonal manipulations of fish reproduction}

they do undergo complete spermatogenesis and spermiation in captivity (Mañanos et al., 2008; Mylonas and Zohar, 2001b; Mylonas and Zohar, 2007; Zohar and Mylonas, 2001b). A reduced amount of milt production represents a serious problem for those species in which hatchery production is based on artificial fertilization and the acquisition of gametes by manual stripping. Production can be limited by difficulties in acquisition of adequate milt from male breeders and may necessitate the use of a much higher number of male breeders than if spawning could occur spontaneously. On the other hand, for species that spawn spontaneously in the tank, the production of highly viscous milt reduces the rapid dispersal of the spermatozoa and thus reduces the sperm fertilization capacity (Vermeirssen et al., 2000). Lower plasma levels of LH during the spermiation period have been suggested as the cause of the reduced amount of milt produced by some fishes (Mañanos et al., 2002; Mylonas and Zohar, 2001a). The amount of LH in the pituitary or the ability of the pituitary to synthesize LH in response to treatment with exogenous GnRHa is not affected in these fishes, suggesting that again the reproductive dysfunction in the males may be identified in the brain control of GtH synthesis and/or release.

\subsection{Females}

The simplest reproductive problem in cultured fishes is observed in cultured salmonids, which do undergo vitellogenesis, OM and ovulation, but fail to spawn their eggs and milt when reared in captivity (Bromage and Cumaranatunga, 1988; Zohar, 1989), probably due to a loss of the spawning behaviour caused by domestication, or the lack of the appropriate spawning substrate to place eggs. This reproductive dysfunction in salmonids is not causing great problems to the industry, as the ovulated eggs remain viable in the abdominal cavity for many days to a few weeks, and can be obtained easily by stripping and fertilized artificially (Craik and Harvey, 1984; Sakai et al., 1975). In fact, this characteristic may be advantageous for a 


\section{Mylonas, Fostier and Zanuy}

commercial hatchery, particularly if used in conjunction with hormone-based synchronization protocols (see later), as it allows (a) collection of eggs from a number of females that have ovulated at different times during the course of a week and (b) fertilization with selected sperm. In other species, however, the need to collect the eggs by stripping is a serious limitation, as the time of ovulation must be predicted with accuracy, as over-ripening may take place in minutes or hours after ovulation (reviewed in Bromage, 1995).

In most other fishes, the reproductive dysfunction often observed in culture is that fish undergo vitellogenesis during the reproductive period, but fail to undergo $\mathrm{OM}$ and, as a result, there is no ovulation and no spawning of eggs (Agulleiro et al., 2006; Barbaro et al., 2002; Berlinsky et al., 1996; Berlinsky et al., 1997; Chen, 2005; Duncan et al., 2003; Fauvel et al., 2008; Ibarra-Castro et al., 2004; Larsson et al., 1997; Marino et al., 2003; Mugnier et al., 2000; Mylonas et al., 2007; Mylonas et al., 2004a; Mylonas and Zohar, 2001a; Yang and Chen, 2004). The endocrine cause of the failure of female fish to undergo OM has been identified to be a dysfunctional release of LH from the pituitary at the end of vitellogenesis. In striped bass, for example, comparison of plasma levels of reproductive hormones between cultured fish that fail to undergo OM and wild fish captured on their spawning grounds showed that a plasma LH surge accompanied $\mathrm{OM}$ and ovulation in wild females, but in females reared in captivity plasma LH levels remained low at the end of vitellogenesis (Mylonas et al., 1997c; Mylonas et al., 1998b; Mylonas and Zohar, 2001a). However, LH was synthesized and stored in the pituitary during vitellogenesis, since levels of LH and its mRNA in the pituitary did not differ between wild and captive females, demonstrating that the problem is one of lack of release and not synthesis in captivity. In addition, mRNA levels of the pituitary receptor for the GnRH most relevant to pituitary LH synthesis were similar between wild and captive females. This suggests that the disruption in $\mathrm{LH}$ release from the pituitaries of captive fish is not due to a dysfunction in 


\section{Broodstock management and hormonal manipulations of fish reproduction}

600

602

604

606

608

pituitary responsiveness, but may be related to the control of pituitary function by the reproductive brain. In fact, differences were observed between wild and captive females undergoing OM, when comparing the pituitary content of the endogenous GnRHs. The GnRH mRNA levels within the brain, however, were similar between the two groups, indicating that the altered pituitary content of GnRH in captive fish may be a result of altered release from the hypothalamus, rather than deficient synthesis (Steven, 2000; Steven et al., 2000).

\section{HORMONAL THERAPIES}

Based on the evidence that the failure of cultured fishes to undergo full spermiation and $\mathrm{OM}$ is the result of diminished LH release from the pituitary, manipulations of reproductive function have focused first on the use of exogenous LH preparations that act directly at the level of the gonad, and more recently on GnRHa --with or without DA-- that releases the endogenous LH stores from pituitary (Fig. 6). Endogenous LH, in turn, acts at the level of the gonad to induce steroidogenesis and the process of OM and spermiation.

Luteinizing hormone preparations include (a) homogenates and purified extracts from the pituitary of mature fish during the reproductive season --most commonly of carp and salmonids- that contain high amounts of LH, and (b) purified human Chorionic Gonadotropin (hCG) that has very strong LH activity (Donaldson and Hunter, 1983; Lam, 1982; Zohar, 1989; Zohar and Mylonas, 2001b). Pituitary homogenates were the first type of exogenous hormonal treatments used by aquaculturists for the induction of maturation and spawning (Fontenele, 1955; Houssay, 1930; Von Ihering, 1937). Today, preparations of carp and salmon pituitary extracts (CPE and SPE, respectively) are purified to various extends, and are available in commercial products with their activity being calibrated using bioassays (Donaldson, 1973; Yaron, 1995). Human CG has 


\section{Mylonas, Fostier and Zanuy}

also been used extensively in hormonal manipulation of reproduction in fishes, as it has been available throughout the world for some time now, and it is purified and of clinical grade and standardized bioactivity. Unlike LH preparations of piscine origin, hCG is often effective in a single dose, presumably due to its long half-life in circulation (Ohta and Tanaka, 1997). This is not related to its heterologous nature in fish, since it has been shown to have a significantly longer half-life compared to the pituitary GtHs both in fish (Fontaine et al., 1984) and humans (Ludwig et al., 2002). Recently, an hCG preparation has been approved for commercial utilization in commercial aquaculture (CHORULON ${ }^{\mathrm{TM}}$, Intervet International bv, The Netherlands).

With the discovery and commercial synthesis of various agonists of $\mathrm{GnRH}(\mathrm{GnRHa})$ for human medicine (Schally, 1978; Ulloa-Aguirre and Timossi, 2000), their use for spawning induction therapies in fish increased rapidly, due to their important advantages over LH preparations. Firstly, GnRHa treatments are not as species-specific as LH ones, due to the high structural similarity of native GnRHis among fishes (Lethimonier et al., 2004) Secondly, being of synthetic nature, GnRHas do not pose a disease transmission threat, as CPE and SPE may do. Thirdly, GnRHas are acting at a higher level of the brain-pituitary-gonad axis and stimulate the release of the endogenous GtHs (LH and FSH) as well as other pituitary hormones that may be important to reproductive functions (Cyr and Eales, 1996; Le Gac et al., 1993; Negatu et al., 1998; Weber et al., 1995), and thus provide for a better integration of reproductive processes. The only approved GnRHa for use in commercial aquaculture is Azagly-nafarelin (GONAZONTM, Intervet International bv, The Netherlands).

As mentioned earlier, in some fishes there is a strong inhibition of basal and GnRHstimulated release of LH by DA. Therefore, administration of DA antagonists (e.g., domperidone, pimozide, reserpine or metoclopramide) prior to the treatment with $\mathrm{GnRHa}$ 


\section{Broodstock management and hormonal manipulations of fish reproduction}

removes the inhibition on the gonadotrophs and enhances the stimulatory effect of GnRHa on LH release. Currently, hormonal manipulations of reproduction using a combined GnRHa/DA antagonist treatment are used mostly in cyprinids (Kaminski et al., 2004; Mikolajczyk et al., 2003; Mikolajczyk et al., 2004; Yaron, 1995), catfishes (Brzuska, 2001; Silverstein et al., 1999; Wen and Lin, 2004) and mullets (Aizen et al., 2005; Arabaci and Sari, 2004; Glubokov et al., 1994). that long-term administration of the hormone would result in improved efficacy (Fontenele, 1955). This is because OM and spermiation often require a prolonged hormonal treatment, given in multiple injections (Carrillo et al., 1995; Dabrowski et al., 1994; Mylonas et al., 1992; Pankhurst et al., 1996; Slater et al., 1994). Such repetitive handling may be stressful and damaging to the brood fish and in situations where the broodfish are very large (e.g., groupers, amberjacks or tunas) or kept outdoors --in ponds or cages -- it is very time consuming and labor intensive to crowd, capture, anaesthetize and inject the fish with hormones. As a result, a variety of hormone-delivery systems have been developed during the last 20 years for use in cultured fishes (Mylonas and Zohar, 2001b). Although a delivery system for LH has also been reported (Sato et al., 1995), the ones employed extensively in aquaculture contain exclusively GnRHa. The GnRHa delivery system may be prepared in the form of implantable cylindrical pellets of cholesterol (Weil and Crim, 1983) or Ethylene-Vinyl Acetate (EVAc) (Mylonas et al., 2007; Zohar, 1996), or in the form of injectable biodegradable microspheres using co-polymers of lactic acid and glycolic acid (LGA) or a co-polymer of fatty acid dimer and sebasic acid (Fad-sa) (Barbaro et al., 2002; Breton et al., 1990; Chang et al., 1995; Mylonas et al., 1997b; Mylonas et al., 1995a; Mylonas and Zohar, 2001a; Zohar, 1988). Although the solid implantable GnRHadelivery systems are easier to use by aquaculturists, the microspheric delivery systems have the 


\section{Mylonas, Fostier and Zanuy}

advantage of being biodegradable and of being able to use the same preparation to treat fish with large variation in size. Upon application, the GnRHa delivery systems release GnRHa for periods from 1 to 5 wks, depending on the preparation (Crim et al., 1988; Mañanos et al., 2002; Mylonas et al., 1998b; Mylonas and Zohar, 2001b; Zohar, 1996).

\subsection{Spermatogenesis and spermiation}

As mentioned earlier, with the exception of the freshwater eels, cultured male fishes do undergo spermatogenesis and spermiation in captivity, but often produce milt of lesser quantity or quality. So, in essence, the objective of hormonal therapies in male cultured fishes is primarily to increase seminal fluid production and secondarily to enhance completion of spermatogenesis (spermiogenesis and spermiation). Due to the long-term nature of the process of spermatogenesis and spermiation, which takes months to weeks (Schulz and Miura, 2002), long-term hormonal therapies with GnRHa-delivery systems have proven more effective in enhancing milt production compared to acute treatments with either LH preparations or GnRHas (Fig. 7). In the rabbitfish (Siganus guttatus), for example, milt production increased significantly $24 \mathrm{~h}$ after GnRHa injection, but returned to pre-treatment levels $48 \mathrm{~h}$ later (Garcia, 1991). In carp, (Cyprinus carpio), daily injections of GnRHa induced a sustained elevation of sperm production for $5 \mathrm{~d}$ by, but milt volume decreased below pre-treatment levels $3 \mathrm{~d}$ after the treatment was interrupted (Takashima et al., 1984). In the winter flounder (Pleuronectes americanus) a single GnRHa injection did not increase milt production, whereas two injections given $24 \mathrm{~h}$ apart induced a significant increase in total expressible milt (Harmin and Crim, 1993). Finally, in the European sea bass a single injection of GnRHa at the end of the spawning season was effective in maintaining milt volume of stripped males for only $3 \mathrm{~d}$, compared to 17 d of GnRHa implants (Rainis et al., 2003). The results indicate that for the induction of a 


\section{Broodstock management and hormonal manipulations of fish reproduction}

696

698

sustained increase in milt production, especially in individuals that are stripped spawned during the reproductive season, a long-term hormonal therapy is necessary, either through the use of multiple injections or controlled-release delivery systems.

Many different GnRHa-delivery systems have been used to enhance spermiation in cultured fishes, and the first applications were in salmonid fishes such as Atlantic salmon (Salmo salar) (Weil and Crim, 1983; Zohar, 1996), rainbow trout (Breton et al., 1990), coho salmon (O. kisutch) (Goren et al., 1995) and chinook salmon (O. tshawystcha) (Solar et al., 1995). In the European seabass, treatment with GnRHa-delivery systems resulted in increased milt production for 28-35 d, compared to $7 \mathrm{~d}$ only when a single injection of GnRHa was given (Mañanos et al., 2002; Sorbera et al., 1996). Also in the striped bass, GnRHa-delivery systems induced increases in milt production for 14 to $20 \mathrm{~d}$ (Mylonas et al., 1997b; Mylonas et al., 1998a). GnRHa implants have also been used in Atlantic halibut to enhance the quality of the sperm, which is extremely viscous and exhibits very little spermatozoa motility towards the end of the spawning season (Vermeirssen et al., 2003), in starry flounder (Platichthys stellatus) to increase milt volume and sperm density (Moon et al., 2003) and in greenback flounder (Rhombosolea tapirina) to increase sperm volume (Lim et al., 2004). Still, in some species simple injections of GnRHa of LH preparations have been employed for the successful enhancement of spermiation, including the Siberian sturgeon (A. baerii) (Williot et al., 2002), the sterlet (Acipenser ruthenus) (Rzemieniecki et al., 2004), the precocious European sea bass (Schiavone et al., 2006) and the minnow (Rhynchocypris oxycephalus) (Park et al., 2002).

\subsection{Oocyte maturation and ovulation}

In females, the hormonal therapies employed in aquaculture may be classified to (a) those for the stimulation/completion of vitellogenesis, so that the oocytes undergo/complete 


\section{Mylonas, Fostier and Zanuy}

vitellogenesis and can then undergo OM and ovulation in response to another hormonal therapy; and (b) those for the induction of OM and ovulation alone (Mañanos et al., 2008). Since the process of vitellogenesis is a long one, lasting for weeks to months, such therapies are cumbersome, expensive and not used very often, with the exception of the freshwater eel (Kagawa et al., 2005; van Ginneken and Maes, 2005). In addition, as mentioned earlier, vitellogenesis is usually completed in most captive reared fishes. Therefore, most of the hormonal therapies for the control of reproduction in female fishes are focused on the induction of $\mathrm{OM}$ and ovulation.

Due to the significant differences both in biology and management, hormonal treatments may be different in species with synchronous ovarian development (single-time and single-batch group-synchronous) and asynchronous ovarian development (multiple-batch group-synchronous and asynchronous) (Tyler and Sumpter, 1996). A single or double GnRHa injection protocol may be effective in synchronous fish (Mylonas et al., 1992), which have all their oocytes developed at the same stage of maturation (Fig. 3A), but GnRHa-delivery systems may be more effective in achieving maximum fecundity in asynchronous species with a long reproductive season (Barbaro et al., 1997; Berlinsky et al., 1996; Larsson et al., 1997; Mugnier et al., 2000; Zohar et al., 1995). Also, if required, strip spawning and artificial insemination (see later) is a good alternative to tank spawning in synchronous fishes, but will result in very poor fecundity in asynchronous species, since the fish mature and ovulate only part of their total season production of vitellogenic oocytes (Fig. 3B), and the stripping process may damage the remaining oocytes.

\subsubsection{Syncrhonous oogenesis}

The use of CPE, SPE and hCG in spawning induction therapies in synchronous fishes, together with information on doses and treatment protocols has been published in previous 


\section{Broodstock management and hormonal manipulations of fish reproduction}

reviews (Donaldson, 1973; Donaldson and Hunter, 1983; Lam, 1982; Mañanos et al., 2008; Zohar and Mylonas, 2001a). Recent examples of the use of LH preparations include the European catfish (Silurus glanis), where $4 \mathrm{mg} \mathrm{Kg}^{-1} \mathrm{CPE}$ induced OM and ovulation, though in a smaller percentage of females compared to a combined GnRHa/DA antagonist treatment (Brzuska, 2001). In the catfish "cachara" (Pseudoplatystoma fasciatum) from Brasil, CPE and hCG were both effective in inducing OM and ovulation (Leonardo et al., 2004). In the Japanese catfish (S. asotus), a single injection of 10,000 IU Kg ${ }^{-1}$ hCG induced OM and ovulation (Kumakura et al., 2003). Also, a single injection of hCG at 1000 or $2000 \mathrm{IU} \mathrm{Kg}^{-1}$ was effective in inducing OM and ovulation in the spotted sea bass (Lateolabrax maculatus) (Lee and Yang, 2002). Finally, in ocellated puffer (Takifugu ocellatus), both single and double injections of 6 $\mathrm{mg} \mathrm{Kg}^{-1} \mathrm{CPE}$ or $2500 \mathrm{IU} \mathrm{Kg}^{-1} \mathrm{hCG}$ were very effective in inducing $\mathrm{OM}$ and ovulation (Chen, 2005), and in pikeperch (Sander lucioperca), either single or multiple injections of $200 \mathrm{IU} \mathrm{Kg}{ }^{-1}$ hCG were effective in inducing ovulation (Zakes and Szczepkowski, 2004).

The aquaculture production of sturgeon (Acipenser spp.) relies exclusively on the production of eggs via hormonal induction of OM and ovulation, whereas fertilization is undertaken artificially. Sturgeon females are evaluated for the completion of vitellogenesis and the extent of the migration of the nucleus by surgical removal of oocytes from the ovary and their in vitro processing (Conte et al., 1988; Williot et al., 1991). The selected mature females may be given sturgeon pituitary extract, CPE, or more recently GnRHa (Burtsev et al., 2002; Chebanov and Billard, 2001; Webb et al., 1999; Williot et al., 2002; Williot et al., 2001; Zhuang et al., 2002), usually in a priming and a resolving injection spaced 10-24 $\mathrm{h}$ apart, and ovulation is accomplished 24-50 $\mathrm{h}$ afterwards. Single treatments with CPE have also been reported to be effective (Williot et al., 2005). 


\section{Mylonas, Fostier and Zanuy}

One of the very first applications of GnRHa in aquaculture included the synchronization of $\mathrm{OM}$ and ovulation in salmonids, as a tool for enhancing broodstock management operations and reducing pre-spawning mortalities (Breton et al., 1990; Crim and Glebe, 1984; Donaldson et al., 1981). Treatment with GnRHa is usually given $<2$ weeks before the onset of natural maturation of the broodstock, and is given in the form of two injections (10-100 $\left.\mu \mathrm{g} \mathrm{Kg}^{-1}\right)$ spaced 3 days apart or in a single application of a GnRHa-delivery system (10-50 $\left.\mu \mathrm{g} \mathrm{Kg}^{-1}\right)$. Both the two GnRHa injection (Mylonas et al., 1992; Sullivan et al., 1989; Van Der Kraak et al., 1985) and GnRHa-delivery system protocols (Breton et al., 1990; Crim et al., 1983; Crim and Glebe, 1984; Goren et al., 1995) induce ovulation in $100 \%$ of the population within 10-14 days after treatment. Single or multiple injections of GnRHa have also been used extensively in other fishes with synchronous ovarian development. In the two-injection protocols, GnRHa is given in a priming dose (5-10\%) and a resolving dose (95-90\%). If a DA antagonist is also used, it is administered together with the priming dose. For example, in the ocellated puffer both a single and double injections of $50 \mu \mathrm{g} \mathrm{Kg}^{-1}$ GnRHa were effective in inducing OM and ovulation (Chen, 2005), while similar results were obtained using 2-4 injections of GnRHa in the bullseye puffer (Spoeroides annulatus) (Duncan et al., 2003). In the grey mullet (Mugil cephalus), two injections of $30 \mu \mathrm{g} \mathrm{Kg}^{-1} \mathrm{GnRHa}$ together with $15 \mathrm{mg} \mathrm{Kg}^{-1}$ of the DA antagonist metoclopramide were very effective in inducing spawning within $24 \mathrm{~h}$ (Aizen et al., 2005). Similarly, two injections of $20 \mu \mathrm{g} \mathrm{Kg}^{-1} \mathrm{GnRHa}$ with $5 \mathrm{mg} \mathrm{Kg}^{-1}$ of the DA antagonist pimozide induced ovulation in $95 \%$ of treated common carp (Mikolajczyk et al., 2004). Two injections of GnRHa in combination with a DA antagonist have been used successfully also in the koi carp (Cyprinus carpio) (Arabaci et al., 2004), lake mullet (Chalcalburnus tarichi) (Arabaci and Sari, 2004) and wild catfish (Silurus asorus) (Wen and Lin, 2004). Finally, a single injection of $20 \mu \mathrm{g} \mathrm{Kg}^{-1}$ GnRHa induced ovulation in tench (Tinca tinca) (Rodríguez et al., 2004). 


\section{Broodstock management and hormonal manipulations of fish reproduction}

GnRHa-delivery systems have also been shown to be very effective in inducing OM,

ovulation and spawning in fishes with synchronous ovarian development (Mylonas and Zohar, 2001b; Mylonas and Zohar, 2007). Whereas a GnRHa-delivery system induced spawning in the yaqui catfish (Ictalurus pricei), combined sGnRHa/DA antagonist or catfish PE treatments were ineffective (Mylonas and Zohar, 2001b). In the tiger puffer (T. rubripes), GnRHa-delivery systems $\left(400 \mu \mathrm{g} \mathrm{Kg}^{-1}\right)$ induced ovulation after 18 and $10 \mathrm{~d}$ in fish with small $(800-900 \mu \mathrm{m})$ and large (900-1000 $\mu \mathrm{m})$ mean oocyte diameter, respectively (Matsuyama et al., 1997). Other examples of applications in synchronous fishes include the bullseye puffer (Duncan et al., 2003), cobia (Rachycentron canadum) (Kilduff et al., 2002), devil stinger (Inimicus japonicus) (Takushima et al., 2003) and common carp (Brzuska and Bialowas, 2002).

\subsubsection{Asynchronous oogenesis}

In fish with asynchronous ovarian development, such as the greater ambejack, GnRHadelivery systems have been used preferentially to injections for the induction of multiple $\mathrm{OM}$ and ovulation cycles (Fig. 8). For example, GnRHa-delivery systems induced two consecutive spawns within $3 \mathrm{~d}$ in white bass (M. chrysops) (Mylonas et al., 1997a) and greater amberjack (Seriola dumerili) (Mylonas et al., 2004c), five spawns in $7 \mathrm{~d}$ in the barramundi (Lates calcarifer) (Almendras et al., 1988), five ovulations in 2 weeks in striped trumpeter (Latris lineate) (Morehead et al., 1998), one to four ovulations within $7 \mathrm{~d}$ in the black sea bass (Centropristis striata) (Watanabe et al., 2003) and seven ovulations in $10 \mathrm{~d}$ in the dusky grouper (E. marginatus) (Marino et al., 2003). The above species are considered to have a multiplebatch group-synchonous ovarian development, and are able to produce a few spawns in irregular intervals during the annual reproductive season. Still, the greatest potential of sustained-release GnRHa-delivery systems is in the induction of OM in asynchronous fishes with daily --or almost 


\section{Mylonas, Fostier and Zanuy}

daily-- ovulation/spawning frequency. Some examples, include the red porgy (Pagrus pagrus), red seabream (P. major) and gilthead seabream (Sparus aurata), which have an asynchronous mode of ovarian development and are capable of undergoing OM and spawning on a 24-h cycle for periods of a few months (Mylonas et al., 2004b; Watanabe and Kiron, 1995; Zohar et al., 1995). While a single injection of GnRHa in the gilthead seabream induced only $20 \%$ of the broodstock to undergo daily spawning, a GnRHa-delivery system induced daily spawning in $>70 \%$ of the broodstock. Similar results have been obtained with the other two species (Matsuyama et al., 1995; Zohar and Mylonas, 2001a). Thus, GnRHa-delivery systems result in significant increases in fecundity, by increasing the number of broodfish undergoing OM, and the number of ovulations per spawning season (Barbaro et al., 2002; Berlinsky et al., 1996; Larsson et al., 1997).

Different GnRHa-delivery systems have been used also to induce multiple spawns in various flatfishes, which often do not mature spontaneously in captivity. In the greenback flounder (Rhombosolea tapirina), for example, GnRHa-delivery systems induced daily ovulations (Poortenaar and Pankhurst, 2000), and in wild-caught summer flounder (Paralichthys dentatus) GnRHa implants induced daily ovulations for 8 d (Berlinsky et al., 1997). Moreover, in fish maintained in captivity for more than a year, the same treatment induced not only ovulation, but also spontaneous spawning (Watanabe et al., 1998). Similarly in turbot (Scophthalmus maximus), treatment with a GnRHa-delivery system induced multiple ovulations in all treated fish compared to 50\% of controls (Mugnier et al., 2000). Also, in the yellowtail flounder (Pleuronectes ferrugineus) different GnRHa-delivery systems induced an average of eight consecutive ovulations, compared to three in control fish, resulting in the production of twice as many eggs and of higher fertilization and hatching percentage than control females 


\section{Broodstock management and hormonal manipulations of fish reproduction}

838

840

842

844

(Larsson et al., 1997). The same two GnRHa-delivery systems have also induced daily spawnings for up to 2 weeks in the Senegal sole (Solea senegalensis) (Agulleiro et al., 2006).

The most recent success of the GnRHa-delivery systems has been in the induction of OM, ovulation and spawning of viable eggs in wild-caught Atlantic bluefin tuna (Thunnus thynnus) reared in sea cage for a period of 1 to 3 years (Mylonas et al., 2007) and in Southern bluefin tuna (T. maccoyii) reared in land-based tanks (M. Deichmann, Clean Seas Tuna Ltd, personal communication). GnRHa administration was done underwater in free swimming fish, since it is not possible to anaesthetizing such large (60-120 Kg) bluefin tunas (Mylonas et al., 2007). The use of the same GnRHa-delivery systems has resulted in the induction of 4 consecutive spawnings in a captive-reared stock at Vibo Valentia, Italy, producing many millions of fertilized eggs, allowing the first larval rearing of Atlantic bluefin tuna in the Mediterranean Sea (G. Demetrio, unpublished data).

\section{ARTIFICIAL INSEMINATION}

Ideally, broodstock should be able to spawn spontaneously in their rearing enclosures (tanks, ponds or cages), even if maturation has been induced hormonally. This allows the fish to express their normal breeding behaviour, release their gametes in synchrony -- thus, producing eggs of high fertilization success, and undergo multiple spawnings in fish with asynchronous ovarian development -- thus, resulting in high seasonal fecundity. Eggs may be collected from the spawning enclosures with various methods, including passive egg collectors fitted on the surface overflow (Liu et al., 2000; Zohar et al., 1995) or active collection with dip nets inside a sea cage (Masuma, 2006; Sawada et al., 2005) for pelagophil fish (i.e., with pelagic, buoyant eggs), or with special containers or mats for fish spawning demersal or adhesive eggs (Huner and Dupree, 1984; Piper et al., 1982). 


\section{Mylonas, Fostier and Zanuy}

However, the natural breeding behavior followed by spontaneous spawning may be lost in aquaculture conditions, and hormonal induction of $\mathrm{OM}$ and spermiation does not ensure spontaneous spawning of the fish -i.e., the timely and synchronous release of both gametes, necessary for the production of fertilized eggs. This may be due to inappropriate tank size, lack of bottom substrate for the preparation of a nest or plant substrate for the adhesion of the eggs, and possibly other reasons that are not yet known. Therefore, for many species it is also necessary to employ artificial gamete collection and fertilization, using strip spawning (Billard et al., 2004; Bromage et al., 1992; Hurvitz et al., 2007; Manning and Crim, 1998; Marino et al., 2003; Suquet et al., 1995; Williot et al., 2005; Yaron, 1995). In addition, artificial insemination methods are worth developing for management reasons. Some inter-species hybrids exhibit valuable traits for aquaculture, but these could not be produced by natural, spontaneous mating (Bartley et al., 2001; Paspatis et al., 1999). The development of biotechnologies such as sex control or polyploidy production depends on gamete aquisition and manipulation (Gomlesky, 2003). Finally, the different mating designs required for genetic improvement programs require to cross a large number of specific groups or individuals, and often at the same time and in the same conditions (Dupont-Nivet et al., 2006), which can be performed only using in vitro fertilization. Such fish genetic improvement is more and more associated with genetic resource preservation, in order to help maintain genetic variability within a fishfarm stock or dissemination of valuable traits (Chao and Liao, 2001).

Artificial insemination methods have been described adequately in previous articles (Alavi et al., 2007; Billard, 1988; Billard et al., 1995a; Scott and Baynes, 1980) and very little has changed in recent years. Briefly, ovulated eggs and mature sperm (i.e., milt) are obtained in separate dry containers using abdominal pressure or surgery, preventing any water and urine contamination. In the earliest applied 'dry' method, milt and eggs were mixed thoroughly and 


\section{Broodstock management and hormonal manipulations of fish reproduction}

insemination was achieved in the ovarian fluid, before adding culture water -- eiter fresh or marine water, depending on species. The later used "wet" method employed culture water immediately after mixing of the milt with the eggs, and insemination was achieved in culture water. In natural spawning, spermatozoa are usually immotile in the milt and forward motility is initiated by dilution with the culture water. Sperm motility lasts for only a very short period of time (Cosson, 2007; Scott and Baynes, 1980; Suquet et al., 1994), thus water or urine contamination during sperm stripping should be avoided, as it may activate sperm before mixing with the eggs.

Spermatozoa face many challenges during insemination (Molony and Sheaves, 2001) and various ways to improve fertilization success have been examined for application in artificial fertilization techniques. One approach is the dilution of milt with an immobilization solution prior to mixing it with the eggs (Linhart et al., 1987), at which time fertilization is initiated with an activating solution. Such activating solutions are chosen in order to optimize the percentage and duration of spermatozoa motility, and the composition of these solutions must be adjusted to each fish species taking into account several factors, such as the qualitative ionic composition, osmotic pressure, and $\mathrm{pH}$ of the milt (Alavi and Cosson, 2005; Alavi and Cosson, 2006; Cosson, 2004). However, to our knowledge, there is no means to supply extraenergy to fish spermatozoa for swimming. The metabolism of fish spermatozoa is speciesspecific and there is variation among species in the relative importance of ATP pools vs ATP synthesis to support motility (Burness et al., 2005; Mansour et al., 2003).

Another parameter which needs to be optimized for artificial insemination protocols is the sperm: egg ratio, which is very variable among fishes (Alavi et al., 2007; Suquet et al., 1995), and the evaluation of the type of sperm motility and velocity needed for the success of fertilization (Cosson, 2007; Martínez-Pastor et al., 2008; Rurangwa et al., 2004), although sperm 


\section{Mylonas, Fostier and Zanuy}

motility has not always been associated well with fertilization success (Cruz-Casallas et al., 2005). The variability in fertilization success of fish spermatozoa raised the question of sperm competition, when pools of sperms from different broodfish are used to maintain genetic variability in the offsprings, and several studies have been performed to analyze relationships between spermatozoa characteristics and offspring genotypes. Spermatozoa velocity has been shown to be the primary determinant of sperm competition success in Atlantic salmon (Salmo salar) (Gage et al., 2004) but the relation is opposite in Atlantic cod (Gadus morhua) (Rudolfsen et al., 2008). However, even after equalizing sperm number for in vitro fertilization with a pool of males in carp (Cyprinus carpio), sperm motility, initial sperm concentration and sperm velocity could not explain all the variability in number of sired offspring (Kaspar et al., 2007). Further studies are needed to understand other underlying mechanisms of sperm competition (Stoltz and Neff, 2006), including those able to explain interaction effects with eggs from different females (Rudolfsen et al., 2008).

In regards to the acquisition of eggs for artificial insemination, one of the most important parameters of successful fertilization is the establishment of the time of ovulation either after natural or hormonally-induced OM. This is because once the eggs are ovulated into the ovarian or abdominal cavity they begin to lose their viability, in a process refered to as overmaturation or over-rippening (see Billard et al., 1986; Bromage, 1995). This process is temperature-dependent and species-specific and in salmonids it may last for a few weeks (Springate et al., 1984), in turbot (Scopthalmus maximus) for 10-20 h (see Bromage, 1995) in Atlantic halibut and chub mackerel (Scomber japonicus) for 4-6 hours (Bromage et al., 1994; Shiraishi et al., 2005), in groupers of the genus Epinephelus for 1-2 h (Tucker, 1994) and in the white bass (Morone saxatilis) and Japanese eel (Anguilla japonica) it is only a few minutes (Mylonas et al., 1996; Ohta et al., 1996). Failure to strip the eggs within the appropriate time 


\section{Broodstock management and hormonal manipulations of fish reproduction}

934

936

interval after ovulation will result in greatly reduced fertilization success. Although it has been reported that there may be seasonal changes in sperm quality (Alavi et al., 2008; Mylonas et al., 2003a; Papadaki et al., 2008), in general, sperm collection can be undertaken at any time during the natural spermiation period or after hormonal stimulation. In addition, sperm from most fishes can be maintained viable without the use of cryopreservation or extenders for many hours (Rainis et al., 2003) to many days (Mylonas et al., 2003a; Papadaki et al., 2008). Therefore, a typical artificial insemination protocol should plan for (a) collection and storage of sperm a few hours before the expected time of ovulation and (b) stripping of the eggs at the appropriate time after hormonal therapy. This procedure will ensure optimal results in fertilization success.

Once insemination is completed (after 5-10 min) eggs are rinsed with plenty of culture water and are placed in incubators. Eggs of pelagophil fishes are incubated in cylidroconical containers, which maintain the eggs in constant motion through the use of water upwelling and aeration. Eggs of species with sticky eggs, such as catfishes, cyprinids or sturgeons, may be first treated to remove the stickyness, using clay, talc suspensions or enzyme solutions (Linhart et al., 2004), or may be incubated as egg masses using "artificial males" (Piper et al., 1982).

\section{GAMETE QUALITY}

Gamete quality may be defined as the capacity of eggs and sperm to give rise to normal developing embryos and pre-larvae, and not only high fertilization and hatching success or low mortality (Bonnet et al., 2007). Gamete quality can be a limiting factor in commercial hatcheries, affecting the quantity and quality of the larvae and fry from a given broodstock. The purpose of this section is not to review the current knowledge of the factors that determine gamete quality in general (see Bobe and Babiak, 0000 in this issue), but to draw the attention to 


\section{Mylonas, Fostier and Zanuy}

some considerations relating to the use of hormonal therapies for the induction of OM, ovulation and spermiation.

A common question in regards to hormonal therapies is their effect on egg quality, compared to naturally ovulating or spawning broodfish (Avery et al., 2004; Bonnet et al., 2007; Papanikos et al., 2003; Slater et al., 1995). These effects may be due to modifications of maternal mRNA and could have delayed consequences on embryonic development (Bonnet et al., 2007). Hormonal therapies are recommended only if a broodstock is not reproducing normally in captivity, or for management purposes, such as to increase synchronization of maturation, or to implement inter-specific hybridization or genetic selection programs. In that respect, it makes little practical difference if the resulting egg quality is slightly, yet significant statistically, reduced compared to naturally spawning, wild populations. Neveretheless, appropriately employed hormonal therapies do not usually have a negative effect on egg quality (Barbaro et al., 1997; Duncan et al., 2003; Gillet et al., 1996; Haffray et al., 2005; Mugnier et al., 2000) and may enhance egg and sperm quality in some instances (Larsson et al., 1997; Vermeirssen et al., 2000). Still, further investigations are needed for some species, especially when starting domestication, to improve spawning induction methods (Avery et al., 2004), and, in some cases, both natural and induced spawning can be used to manage a stock of breeders

974 (Watanabe et al., 2001). The main factors that may have significant consequences on gamete quality --mainly eggs-- and should be considered when choosing a spawning induction procedure include (a) the developmental stage of the gonads at the time the hormonal therapy is applied, (b) the type of hormonal therapy, (c) the possible stress induced by the manipulation necessary for the hormone administration, and, (d) in the case of artificial insemination, the latency period between hormonal stimulation and stripping for in vitro fertilization. 


\section{Broodstock management and hormonal manipulations of fish reproduction}

done in freshwater eels, the aim is to stimulate gametogenesis (Kagawa et al., 2005). However, spawning induction protocols are applied at the end of gametogenesis to induce $\mathrm{OM}$ in the females and enhance spermiation in the males. In females, if a hormonal treatment in given too early in the breeding season, when vitellogenesis has not yet been completed in some individuals, the therapy may fail to induce spawning or may give eggs of poor quality (Gardes et al., 2000), whereas on the other hand spawning induction performed too late, at the end of the breeding season may also prove unsuccessful (Carral et al., 2003). and Mylonas, 2001b) and the method of its delivery (Barbaro et al., 2002; Gardes et al., 2000; Mylonas and Zohar, 2001b; Szabó, 2001) may also affect egg quality, whereas sperm quality could be less variable due to the type of hormonal treatment (Miranda et al., 2005). A too high level of hormone can also have deleterious effects on egg quality (Gardes et al., 2000; Mylonas et al., 1992), especially in the form of a single injection, whereas hormone-delivery systems give more satisfactory results (Mylonas and Zohar, 2001b). Controlled-release delivery systems for reproductive hormones (mainly GnRHa) produce a long-term elevation in plasma gonadotropins, thus providing a better stimulation of OM and spermiation, resulting in gametes of better quality, especially in fish with asynchronous ovarian development. In addition, hormone-delivery systems are more advantageous than hormone injections in terms of handling stress, as they are effective after a single administration and reduce the excessive and often very damaging handling of the broodfish (Agulleiro et al., 2006; Mugnier et al., 1998). In addition, some hormone delivery systems can be administered underwater in moving fish, in situations where handling and anesthesia is not feasible (Harvey et al., 1988; Mylonas et al., 2007). 


\section{Mylonas, Fostier and Zanuy}

Finally, in the case of species that do not spawn spontaneously after ovulation in 1004 captivity and fertilization is achieved artificially after stripping, it has been shown that the latency period, during which the eggs remain in the ovarian or abdominal cavity after ovulation and before stripping is directly related to loss of egg quality (Bromage et al., 1994). The latency period depends on both intrinsic (Wendling et al., 2000) and environmental parameters (Brzuska, 1999), some of which include species, water temperature (Yaron, 1995), type of hormone and dose (Wen and Lin, 2004), as well as the history of fish in the preceding period (e.g., low vs high temperatures) (Tveiten et al., 2001; Van Der Kraak and Pankhurst, 1996) and the stage of ovarian maturity at the time of the hormone treatment (Matsuyama et al., 1997). Therefore, the latency period of each species under the specific hormonal induction protocol and hatchery conditions must be thoroughly examined in order to achieve high spawning success together with high egg quality. 


\section{Broodstock management and hormonal manipulations of fish reproduction}

\section{REFERENCES}

Agulleiro, M. J., Anguis, V., Cañavate, J. P., Martínez-Rodríguez, G., Mylonas, C. C., Cerdá, J., 2006. Induction of spawning of captive-reared Senegal sole (Solea senegalensis) using different administration methods for gonadotropin-releasing hormone agonist. Aquaculture. 257: 511-524.

Aizen, J., Meiri, I., Tzchori, I., Levavi-Sivan, B., Rosenfeld, H., 2005. Enhancing spawning in the grey mullet (Mugil cephalus) by removal of dopaminergic inhibition. Gen. Comp. Endocrinol. 142: 212-221.

Alavi, H. S. M., Cosson, J., 2005. Sperm motility in fishes. I. Effects of temperature and pH: a review. Cell Biology International. 29: 101-110.

Alavi, H. S. M., Cosson, J., 2006. Sperm motility in fishes. (II) Effects of ions and osmolalilty: a review. Cell Biology International. 30:1-14.

Alavi, H. S. M., Psenicka, M., Rodina, M., Pollicar, T., Linhart, O., 2008. Changes of sperm morphology, volume, density and motility and seminal plasma composition in Barbus barbus (Teleostei: Cyprinidae) during the reproductive season. Aquat. Living Resour. 21: 75-80.

Alavi, S. M. H., Linhart, O., Cowand, K., Rodina, M., 2007. Fish spermatology: implications for aquacultûre management. In: Alavi, S.M.H., Cosson, J., Coward, K., Rafiee, G., (Eds.), Fish Spermatology. Alpha Science Intl, Oxford (UK), pp. 397-461.

Almendras, J. M., Duenas, C., Nacario, J., Sherwood, N. M., Crim, L. W., 1988. Sustained hormone release. III. Use of gonadotropin releasing hormone analogues to induce multiple spawnings in sea bass, Lates calcarifer. Aquaculture. 74: 97-111. 


\section{Mylonas, Fostier and Zanuy}

1040

1042

Amano, H., Fujita, T., Hiramatsu, N., Kagawa, H., Matsubara, T., Sullivan, C. V., Hara, A., 2008. Multiple vitellogenin-derived yolk proteins in Gray mullet (Mugil cephalus): Disparate proteolytic patterns associated with ovarian follicle maturation. Mol. Repro. Dev. 75: 13071317.

Appelt, W., Sorensen, P. W., 2007. Female goldfish signal spawning readiness by altering when and where they release a urinary pheromone. Anim. Behav. 74: 1329-1338.

Arabaci, M., Cagirgan, H., Sari, M., 2004. Induction of ovulation in ornamental common carp (Koi, Cyprinus carpio L.) using LHRHa ([d-Ser(tBu $)^{6}$, Pro $\left.\left.{ }^{9}-\mathrm{NEt}\right]-\mathrm{LHRH}\right)$ combined with haloperidol and carp pituitary extract. Aqua. Res. 35: 10-14.

Arabaci, M., Sari, M., 2004. Induction of ovulation in endemic pearl mullet (Chalcalburnus tarichi), living in the highly alkaline Lake Van, using GnRHa ([d-Ser(tBu) $\left.{ }^{6}, \operatorname{Pro}^{9}-\mathrm{NEt}\right]-$ GnRH) combined with haloperidol. Aquaculture. 238: 529-535.

Asahina, K., Barry, Y. P., Aida, K., Fusetani, N., Hanyu, I., 1990. Biosynthesis of 17a,20adihydroxy-4-pregnen-3-one from 17a-hydroxyprogesterone by spermatozoa of the common carp. J. Exp. Zool. 255: 244-249.

Asturiano, J. F., Sorbera, L. A., Ramos, J., Kime, D. E., Carrillo, M., Zanuy, S., 2000. Hormonal regulation of the European seabass reproductive cycle: an individualized female approach. J. Fish Biol. 56: 1155-1172.

Avery, T. S., Boyce, D., Brown, J. A., 2004. Mortality of yellowtail flounder, Limanda ferruginea (Storer), eggs: effects of temperature and hormone-induced ovulation. Aquaculture. 230: 297-311.

Babin, P. J., Carnevali, O., Lubzens, E., Schneider, W. J., 2007. Molecular aspects of oocyte vitellogenesis in fish. In: Babin, P.J., Cerdá, J., Lubzens, E., (Eds.), The Fish Oocyte: From Basic Studies to Biotechnological Applications. Springer, The Netherlands, pp. 39-76. 


\section{Broodstock management and hormonal manipulations of fish reproduction}

1064

1066

1068

Barbaro, A., Francescon, A., Bozzato, G., Merlin, A., Belvedere, P., Colombo, L., 1997. Induction of spawning in gilthead seabream, Sparus aurata L., by long-acting GnRH agonist and its effects on egg quality and daily timing of spawning. Aquaculture. 154: 349-359.

Barbaro, A., Franceson, A., Bertotto, D., Bozzato, G., Di Maria, I., Patarnello, P., Furlan, F., Colombo, L., 2002. More effective induction of spawning with long-acting GnRH agonist in the shi drum, Umbrina cirrosa L. (Sciaenidae, Teleostei), a valuable candidate for Mediterranean mariculture. J. Appl. Ichthyol. 18: 192-199.

Barry, T., Aida, K., Okumura, T., Hanyu, I., 1990. The shift from C-19 to C-21 steroid synthesis in spawning male common carp, Cyprinus carpio, is regulated by the inhibition of androgen production by progestogens produced by spermatozoa. Biol. Reprod. 43: 105-112.

Bartley, D. M., Rana, K., Immink, A. J., 2001. The use of inter-specific hybrids in aquaculture and fisheries. Rev. Fish Biol. Fish. 10: 325-337.

Beardsley, A., O’Donnell, L., 2003. Characterization of normal spermiation and spermiation failure induced by hormone suppression in adult rats. Biol. Reprod. 68: 1299-1307.

Berlinsky, D. L., King, W. V., Smith, T. I. J., Hamilton, R. D., II, Holloway, J., Jr., Sullivan, C. V., 1996. Induced ovulation of Southern flounder Paralichthys lethostigma using gonadotropin releasing hormone analogue implants. J. World Aquac. Soc. 27: 143-152.

Berlinsky, D. L., William, K., Hodson, R. G., Sullivan, C. V., 1997. Hormone induced spawning of summer flounder Paralichthys dentatus. J. World Aquac. Soc. 28: 79-86.

Billard, R., 1986. Spermatogenesis and spermatology of some teleost fish species. Reprod. Nutr. Develop. 26: 877-920.

Billard, R., 1988. Artificial insemination and gamete management in fish. Mar. Fresh. Behav. Physiol. 14, 3-21.

Billard, R., 1989. Endocrinology and fish culture. Fish Physiol. Biochem. 7: 49-58. 


\section{Mylonas, Fostier and Zanuy}

1088

1090

1092

Billard, R., Christen, R., Cosson, J., Gatty, J. L., Letellier, L., Renard, P., Saad, A., 1986.

Biology of gametes of some teleost species. Fish Physiol. Biochem. 2: 115-130.

Billard, R., Cosson, J., Crim, L. W., Suquet, M., 1995a. Sperm physiology and quality. In: Bromage, N.R., Roberts, R.J., (Eds.), Broodstock Management and Egg and Larval Quality. Blackwell Science, Oxford, pp. 25-52.

Billard, R., Cosson, J., Noveiri, S. B., Pourkazemi, M., 2004. Cryopreservation and short-term storage of sturgeon sperm, a review. Aquaculture. 236: 1-9.

Billard, R., Cosson, J., Perchec, G., Linhart, O., 1995b. Biology of sperm and artificial reproduction in carp. Aquaculture. 129: 95-112.

Billard, R., Le Gac, F., Loir, M., 1990. Hormonal control of sperm production in teleost fish. Progress in Comparative Endocrinology. WIley-Liss, Inc.

Bobe, J., Babiak, I., 0000. Gamete quality. Gen. Comp. Endocrinol. 000: 000-000.

Bobe, J., Jalabert, B., Fostier, A., 2008. Oogenesis: post-vitellogenic events leading to a fertilizable oocyte. In: Rocha, B.G., Arukwe, M.J., Kapoor, A., (Eds.), Fish Reproduction. Science Publishers, Enfield, pp. 1-36.

Bonnet, E., Fostier, A., Bobe, J., 2007. Microarray-based analysis of fish egg quality after natural or controlled ovulation. BMC Genomics. 8:55.

Breton, B., Weil, C., Sambroni, E., Zohar, Y., 1990. Effects of acute versus sustained administration of GnRHa on GtH release and ovulation in the rainbow trout, Oncorhyncus mykiss. Aquaculture. 91: 371-383.

Bromage, N., Bruce, M., Basavaraja, N., Rana, K., Shields, R., Young, C., Dye, J., Smith, P., Gillespie, M., Gamble, J., 1994. Egg quality determinants in finfish: the role of overripening with special reference to the timing of stripping in the Atlantic halibut Hippoglossus hippoglossus. J. World Aquac. Soc. 25: 13-21. 


\section{Broodstock management and hormonal manipulations of fish reproduction}

1112

Bromage, N., Jones, J., Randall, C., Thrush, M., Springate, J., Duston, J., Barker, G., 1992. Broodstock management, fecundity, egg quality and the timing of egg production in the rainbow trout (Oncorhynchus mykiss). Aquaculture. 100: 141-166.

Bromage, N., Porter, M., C., R., 2001. The environmental regulation of maturation in farmed finfish with special reference to the role of photoperiod and melatonin. Aquaculture. 197: 6398.

Bromage, N. R., 1995. Broodstock management and seed quality - general considerations. In: Bromage, N.R., Roberts, R.J., (Eds.), Broodstock Management and Egg and Larval Quality. Blackwell Science, Oxford, pp. 1-24.

Bromage, N. R., Cumaranatunga, R., 1988. Egg production in the rainbow trout. In: Muir, J.F., Roberts, R.J., (Eds.), Recent Advances in Aquaculture. Croom Helm/Timber Press Inc., London, pp. 63-138.

Brooks, S., Tyler, C. R., Sumpter, J. P., 1997. Egg quality in fish: what makes a good egg? Rev. Fish Biol. Fish. 7: 387-416.

Brzuska, E., 1999. Artificial spawning of herbivorous fish: use of an LHRH-a to induce ovulation in grass carp Ctenopharyngodon idella (Valenciennes) and silver carp Hypophthalmichthys molitrix (Valenciennes). Aqua. Res. 30: 849-856.

Brzuska, E., 2001. Artificial spawning of European catfish Silurus glanis L.: differences between propagation results after stimulation of ovulation with carp pituitary and Ovopel. Aquacult. Int. 32: 11-19.

Brzuska, E., Bialowas, H., 2002. Artificial spawning of carp, Cyprinus carpio (L.). Aqua. Res. 33: 753-765. 


\section{Mylonas, Fostier and Zanuy}

Buchet, V., Coquard, E., Sévère, A., Barone, H., 2008. Influence of tank volume on vitellogenesis and spawning performances in sea bass Dicentrarchus labrax L. Aqua. Res. 39: 420-426.

Burness, G., Moyes, C. D., Montgomerie, R., 2005. Motility, ATP levels and metabolic enzyme activity of sperm from bluegill (Lepomis macrochirus). Comp. Biochem. Physiol. A140. 1117.

Burtsev, I. A., Nikolaev, A. I., Maltsev, S. A., Igumnova, L. V., 2002. Formation of domesticated broodstocks as a guarantee of sustainable hatchery reproduction of sturgeon for sea ranching. J. Appl. Ichthyol. 18: 655-658.

Carral, J. M., Rodriguez, R., Celafda, J. D., Saez-Royuela, A., Aguilera, A., Melendre, P., 2003. Successful gonadal development and maturation of tench (Tinca tinca L.) in small concrete ponds. J. Appl. Ichthyol. 19:130-131.

Carrillo, M., Zanuy, S., Prat, F., Cerda, J., Ramos, J., Mañanos, E., Bromage, N., 1995. Sea bass (Dicentrarchus labrax). In: Bromage, N.R., Roberts, R.J., (Eds.), Broodstock Management and Egg and Larval Quality. Blackwell Science, Oxford, pp. 138-168.

Carrillo, M., Zanuy, S., Prat, F., Serrano, R., Bromage, N., 1993. Environmental and hormonal control of reproduction in sea bass. In: Muir, J.F., Roberts, R.J., (Eds.), Recent Advances in Aquaculture, volume IV. Institute of Aquaculture, Blackwell Scientific Publications, Oxford, pp. $43-54$.

Cerdá, J., Fabra, M., Raldúa, D., 2007. Physiological and molecular basis of fish oocyte hydration. In: Babin, P.J., Cerdá, J., Lubzens, E., (Eds.), The Fish Oocyte: from Basic Studies to Biotechnological Applications. Kluwer Academic Publishers, Dordrecht, The Netherlands, pp. 349-396. 


\section{Broodstock management and hormonal manipulations of fish reproduction}

Cerdá, J., Selman, K., Wallace, R. A., 1996. Observations on oocyte maturation and hydration in vitro in the black sea bass, Centropristis striata (Serranidae). Aquat. Living Resour. 9: 325335.

Chang, C. F., Yueh, W. S., Lee, M. F., Schally, A. V., 1995. A microencapsulated analog of LH$\mathrm{RH}$ accelerates maturation but without stimulating sex reversal in the protandrous black porgy, Acanthopagrus schlegeli. Reprod. Nutr. Develop. 35: 339-349.

Chang, J. P., Jobin, R. M., 1994. Regulation of gonadotropin release in vertebrates: a comparison of GnRH mechanisms of action. In: Davey, K.G., Peter, R.E., Tobe, S.S., (Eds.), Perspectives in Comparative Endocrinology. National Research Council of Canada, Ottawa, pp. 41-51.

Chao, N. H., Liao, I. C., 2001. Cryopreservation of finfish and shellfish gametes and embryos. Aquaculture. 197: 161-180.

Chaves-Pozo, E., Mulero, V., Meseguer, J., Ayala, A. G., 2005. An overview of cell renewal in the testis throughout the reproductive cycle of a seasonal breeding teleost, the glthead seabream (Sparus aurata L.). Biol. Reprod. 72:593-601.

Chebanov, M., Billard, R., 2001. The culture of sturgeons in Russia: production of juveniles for stocking and meat for human consumption. Aquat. Living Resour. 14: 375-381.

Chemineau, P., Malpaux, B., Brillard, J. P., Fostier, A., 2007. Seasonality of reproduction and production in farm fishes, birds and mammals. Animal. 1: 419-432. ocellatus. J. Appl. Ichthyol. 21: 136-140.

Chowdhury, I., Joy, K. P., 2007. Seminal vesicle and its role in the reproduction of teleosts. Fish Physiol. Biochem. 33: 383-398. 


\section{Mylonas, Fostier and Zanuy}

1180 Clearwater, S. J., Crim, L. W., 1998. Gonadotropin releasing hormone-analogue treatment increases sperm motility, seminal plasma $\mathrm{pH}$ and sperm production in yellowtail flounder Pleuronectes ferrugineus. Fish Physiol. Biochem. 19: 349-357.

Conte, F. S., Doroshov, S. I., Lutes, P. B., Strange, E. M., 1988. Hatchery manual for the white sturgeon (Acipenser transmontanus Richardson) with application to other North American Acipenseridae. Cooperative Extension University of California. Division o Agriculture and Natural Resources.

Corriero, A., Medina, A., Mylonas, C. C., Abascal, F. J., Deflorio, M., Aragón, L., Bridges, C. R., Santamaria, C. A., Heinisch, G., Vassallo-Agius, R., Belmonte, A., Fauvel, C., Garcia, A., Gordin, H., De Metrio, G., 2007. Histological study of the effects of treatment with

Cosson, J., 2004. The ionic and osmotic factors controlling motility of fish spermatozoa. Aquacult. Int. 12: 69-85.

Cosson, J., 2007. Methods to analyse the movements of fish spermatozoa and their flagella. In: Alavi, S.M.H., Cosson, J., Coward, K., Rafiee, G., (Eds.), Fish Spermatology. Alpha Science Intl, Oxford, UK, pp. 63-102.

Craik, J. C. A., Harvey, S. M., 1984. Egg quality in rainbow trout: the relation between egg viability, selected aspects of egg composition and time of stripping. Aquaculture. 40: 115134.

Crim, L. W., Evans, D. M., Vickery, B. H., 1983. Manipulation of the seasonal reproductive cycle of the landlocked Atlantic salmon (Salmo salar) by LHRH analogues administered at various stages of gonadal development. Can. J. Aquat. Fish. Sci. 40: 61-67. 


\section{Broodstock management and hormonal manipulations of fish reproduction}

Crim, L. W., Glebe, B. D., 1984. Advancement and synchrony of ovulation in Atlantic salmon with pelleted LHRH analog. Aquaculture. 43: 47-56.

Crim, L. W., Sherwood, N. M., Wilson, C. E., 1988. Sustained hormone release. II. Effectiveness of LHRH analog (LHRHa) administration by either single time injection or cholesterol pellet implantation on plasma gonadotropin levels in a bioassay model fish, the juvenile rainbow trout. Aquaculture. 74: 87-95.

Cruz-Casallas, P. E., Lombo-Rodriguez, D. A., Velasco-Santamaria, Y. M., 2005. Milt quality and spermatozoa morphology of captive Brycon siebenthalae (Eigenmann) broodstock. Aqua. Res. 38: 682-686.

Cyr, D. G., Eales, J. G., 1996. Interrelationships between thyroidal and reproductive endocrine systems in fish. Rev. Fish Biol. Fish. 6: 165-200.

Dabrowski, K., Ciereszko, A., Ramseyer, L., Culver, D., Kestemont, P., 1994. Effects of hormonal treatment on induced spermiation and ovulation in the yellow perch (Perca flavescens). Aquaculture. 120: 171-180.

De Montgolfier, B., Dufresne, J., Letourneau, M., Nagler, J., Fournier, A., Aude, t. C., Cyr, D. G., 2007. The expression of multiple connexins throughout spermatogenesis in the rainbow trout testis suggests a role for complex intercellular communication. Biol. Reprod. 76, 2-8.

Denson, M. R., Jenkins, W. E., Berlinsky, D. L., Smith, T. I. J., 2007. A comparison of human chorionic gonadotropin and luteinizing hormone releasing hormone analogue for ovulation induction in black sea bass Centropristis striata (Linnaeus, 1758). Aqua. Res. 38: 918-925.

Donaldson, E. M., 1973. Reproductive endocrinology of fishes. Amer. Zool. 13: 909-927.

Donaldson, E. M., Hunter, G. A., 1983. Induced final maturation, ovulation and spermiation in cultured fishes. In: Hoar, W.S., Randall, D.J., Donaldson, E.M., (Eds.), Fish Physiology. Academic Press, Orlando, Florida, pp. 351-403. 


\section{Mylonas, Fostier and Zanuy}

Donaldson, E. M., Hunter, G. A., Dye, H. M., 1981. Induced ovulation in coho salmon (Oncorhynchus kisutch). II. Preliminary study of the use of LH-RH and two high potency LH-RH analogues. Aquaculture. 26: 129-141.

Drori, S., Ofir, M., Levavi-Sivan, B., Yaron, Z., 1994. Spawning induction in common carp (Cyprinus carpio) using pituitary extract or GnRH superactive analogue combined with metoclopramide: analysis of hormone profile, progress of oocyte maturation and dependence on temperature. Aquaculture. 119: 393-407.

Duarte, M., Marbá, N., Holmer, M., 2007. Rapid domestication of marine species. Science. 16: $382-383$

Duncan, N. J., Rodriguez M. de O., G. A., Alok, D., Zohar, Y., 2003. Effects of controlled delivery and acute injections of LHRHa on bullseye puffer fish (Sphoeroides annulatus) spawning. Aquaculture. 218: 625-635.

Dupont-Nivet, M., Vandeputte, M., Haffray, P., Chevassus, B., 2006. Effect of different mating designs on inbreeding, genetic variance and response to selection when applying individual selection in fish breeding programs. Aquaculture. 252: 161-170.

El Naggar, G. O., John, G., Rezk, M. A., Elwan, W., Yehia, M., 2006. Effect of varying density and water level on the spawning response of African catfish Clarias gariepinus: Implications for seed production. Aquaculture. 261: 904-907.

Fauvel, C., Savoye, O., Dreanno, C., Cosson, J., Suquet, M., 1999. Characteristics of sperm of captive seabass in relation to its fertilization potential. J. Fish Biol. 54: 356-369.

Fauvel, C., Suquet, M., Sévère, A., Mylonas, C. C., Papandroulakis, N., 2008. Slow-release GnRHa therapy prevented atresia during vitellogenesis and induced ovulation of captive wreckfish (Polyprion americanus). Cybium. 32(2) suppl: 191. 


\section{Broodstock management and hormonal manipulations of fish reproduction}

1250

Finn, R. N., 2007. The maturational disassembly and differential proteolysis of paralogous vitellogenins in a marine pelagophil teleost: A conserved mechanism of oocyte hydration. Biol. Reprod. 76: 936-948.

Finn, R. N., Østby, G. C., Norberg, B., Fyhn, H. J., 2002. In vivo hydration in Atlantic halibut (Hippoglossus hippoglossus); proteolytic liberation of free amino acids, and ion transport, are driving forces for osmotic water influx. J. Exp. Biol. 205: 211-224.

Fishelson, L., Gon, O., V., H., Delarea, Y., 2007. Comparative spermatogenesis, spermatocytogenesis, and spermatozeugmata formation in males of viviparous species of clinid fishes (Teleostei: Clinidae, Blennioidei). The Anatomical Record. 290: 311-323.

Fontaine, Y. A., Dufour, S., Tanguy, G., Khan, I. A., Cedard, L., Leloup-Hatey, J., Clairances metaboliques de la gonadotropine chorionique humaine (hCG) et de la gonadotropin de carpe (cGtH) chez un poisson teleosteen, l'anguille. Colloque Physiologie des Poissons. INRA and IFREMER, 1984.

Fontenele, O., 1955. Injecting pituitary (hypophyseal) hormones into fish to induce spawning. Prog. Fish-Cult. 18: 71-75.

Forniés, M. A., Carrillo, M., Mañanos, E., Sorbera, L. A., Zohar, Y., Zanuy, S., 2003. Relative potencies of the forms of GnRH and their analogs on LH release in sea bass. J. Fish Biol. 63: 73-89.

Forniés, M. A., Mañanos, E., Carrillo, M., Rocha, A., Laureau, S., Mylonas, C. C., Zohar, Y., Zanuy, S., 2001. Spawning induction of individualised European seabass females (Dicentrarchus labrax) using different GnRHa-delivery systems. Aquaculture. 202: 221-234.

Gage, M. J. G., Macfarlane, C. P., Yeates, S., Ward, R. G., Searle, J. B., Parker, G. A., 2004. Spermatozoal traits and sperm competition in Atlantic salmon: relative sperm velocity is the primary determinant of fertilization success. Current Biology. 14: 44-47. 


\section{Mylonas, Fostier and Zanuy}

1274

1276

1278

Garcia, L. M. B., 1989. Development of an ovarian biopsy technique in the sea bass, Lates calcarifer. Aquaculture. 77: 97-102.

Garcia, L. M. B., 1991. Spermiation response of mature rabbitfish, Siganus guttatus Bloch, to luteinizing hormone-releasing hormone analogue (LHRHa) injection. Aquaculture. 97: 291299.

Gardes, L., Villanove, P., Buchet, V., Fauvel, C., 2000. Induced spawning of red drum, Sciaenops ocellatus: use of multivariate and univariate analysis methods in the search for side effects of LH-RHa treatments and ovarian development state upon spawn quality. Aquat. Living Resour. 13:19-27.

Gillet, C., Breton, B., Mikolajczyk, T., 1996. Effects of GnRHa and pimozide treatments on the timing of ovulation and on egg quality in Arctic charr (Salvelinus alpinus) at 5 and $10^{\circ} \mathrm{C}$. Aquat. Living Resour. 9: 257-263.

Glasser, F., Mikolajczyk, T., Jalabert, B., Baroiller, J.-F., Breton, B., 2004. Temperature effects along the reproductive axis during spawning induction of grass carp (Ctenopharyngodon idella). Gen. Comp. Endocrinol. 136: 171-179.

Glubokov, A. I., Kouril, J., Mikodina, E. V., Barth, T., 1994. Effects of synthetic GnRH analogues and dopamine antagonists on the maturation of Pacific mullet, Mugil so-iuy Bas. Aquaculture and Fisheries Management. 25: 419-425.

Gomez, J. M., Weil, C., Ollitrault, M., Le Bail, P. Y., Breton, B., Le Gac, F., 1999. Growth hormone $(\mathrm{GH})$ and gonadotropin subunit gene expression and pituitary and plasma changes during spermatogenesis and oogenesis in rainbow trout (Oncorhynchus mykiss). Gen. Comp. Endocrinol. 113: 413-428.

Gomlesky, B., 2003. Chromosome set manipulation and sex control in common carp: a review. Aquat. Living Resour. 16: 408-415. 


\section{Broodstock management and hormonal manipulations of fish reproduction}

1298

1300

1302

Goren, A., Gustafson, H., Doering, D., 1995. Field trials demonstrate the efficacy and commercial benefit of a GnRHa implant to control ovulation and spermiation in salmonids. In: Goetz, F.W., Thomas, P., (Eds.), Reproductive Physiology of Fish. Fish Symposium 95, Austin, Texas, pp. 99-101.

Haddy, J. A., Pankhurst, N. W., 2000. The effects of salinity on reproductive development, plasma steroid levels, fertilisation and egg survival in black bream Acanthopagrus butcheri. Aquaculture. 188: 115-131.

Haffray, P., Enright, W. J., Driancourt, M. A., Mikolajczyk, T., Rault, P., Breton, B., 2005. Optimization of breeding of salmonids: Gonazon ${ }^{\mathrm{TM}}$, the first officially approved inducer of ovulation in the EU. Aquaculture Magazine. March: 52-56.

Haffray, P., Fostier, A., Normant, Y., Fauré, A., Loir, M., Jalabert, B., Maisse, G., Le Gac, F., 1995. Effect of seawater rearing or freshwater transfer on final maturation and gamete quality in Atlantic salmon, Salmo salar. Aquat. Living Resour. 8: 135-145.

Harmin, S. A., Crim, L. W., 1993. Influence of gonadotropin hormone-releasing hormone analog (GnRH-A) on plasma sex steroid profiles and milt production in male winter flounder, Pseudopleuronectes americanus (Walbaum). Fish Physiol. Biochem. 10: 399-407.

Harvey, B., Denny, C., Kaiser, S., Young, J., 1988. Remote intramuscular injection of immobilising drugs into fish using a laser-aimed underwater dart gun. The Veterinary Record. 122: $174-177$.

Hiramatsu, N., Matsubara, T., Fujita, T., Sullivan, C. V., Hara, A., 2006. Multiple piscine vitellogeniins: biomarkers of fish exposure to estrogenic endocrine disruptors in aquatic environments. Mar. Biol. 149: 35-47. 


\section{Mylonas, Fostier and Zanuy}

Hiramatsu, N., Matsubara, T., Hara, A., Donato, D. M., Hiramatsu, K., Denslow, N. D., Sullivan, C. V., 2002. Identification, purification and classification of multiple forms of vitellogenin from white perch (Morone americana). Fish Physiol. Biochem. 26: 355-370.

Hong, W.-S., Chen, S.-X., Zhang, Q.-Y., Zheng, W.-Y., 2006. Sex organ extracts and artificial hormonal compounds as sex pheromones to attract broodfish and to induce spawning of Chinese black sleeper (Bostrichthys sinensis Lacépêde). Aqua. Res. 37: 529-534.

Houssay, B. A., 1930. Accion sexual de la hipofisis en los peces y reptiles. Rev. Soc. Arg. Biol. 106: 686-688.

Huner, J. V., Dupree, H. K., 1984. Methods and economics of channel catfish production, and techniques for the culture of flathead catfish and other catfishes. In: Dupree, H.K., Huner, J.V., (Eds.), Third Report to the Fish Farmers. The Status of Warmwater Fish Farming and Progress in Fish Farming Research. U.S. Fish and Wildlife Service, Washington, D.C., pp. 44-82.

Hurvitz, A., Jackson, K., Degani, G., Levavi-Sivan, B., 2007. Use of endoscopy for gender and ovarian stage determinations in Russian sturgeon (Acipenser gueldestaedtii) grown in aquauculture. Aquaculture. 270: 158-166.

Ibarra-Castro, L., Dumas, S., Duncan, N., Gonad development and LHRHa induced spawning in female rosey spotted snapper Lutjanus gutattus. 5th International Symposium on Fish Endocrinology, Castellon, Spain, 2004.

Ibarra-Castro, L., Dunca, N. J., 2007. GnRHa-induced spawning of wild-caught spotted rose snapper Lutjanus guttatus. Aquaculture. 272: 737-746.

Jackson, L. F., Sullivan, C. V., 1995. Reproduction of white perch: the annual gametogenic cycle. Trans. Amer. Fish. Soc. 124: 563-577. 


\section{Broodstock management and hormonal manipulations of fish reproduction}

Jalabert, B., 2005. Particularities of reproduction and oogenesis in teleost fish compared to mammals. Reprod. Nutr. Develop. 45: 261-279.

Kagawa, H., Tanaka, H., Ohta, H., Unuma, T., Nomura, K., 2005. The first success of glass eel production in the world: basic biology on fish reproduction advances new applied technology in aquaculture. Fish Physiol. Biochem. 31: 193-199.

Kaminski, R., Kusznierz, J., Myszkowski, L., Wolnicki, J., 2004. The first attempt to artificially reproduce the endangered cyprinid lake minnow Eupallasella perenurus (Pallas). Aquacult. Int. 12: 3-10.

Kaspar, V., Kohlmann, K., Vandeputte, M., Rodina, M., Gela, D., Kocour, M., Alavi, H. S. M.,

Kilduff, P., DuPaul, W., Oesterling, M., Olney, J., Jr., Tellock, J., 2002. Induced spawning of cobia, Rachycentron canadum, and early larval husbandry. World Aquaculture. 33: 35-38.

Kime, D. E., 1979. The effect of temperature on the testicular steroidogenic enzymes of the rainbow trout, Salmo gairdneri. Gen. Comp. Endocrinol. 39: 290-296.

King, H. R., Pankhurst, N. W., 2007. Additive effects of advanced temperature and photoperiod regimes and LHRHa injection on ovulation in Atlantic salmon (Salmo salar). Aquaculture. 273: 729-738.

King, W., V., Ghosh, S., Thomas, P., Sullivan, C. V., 1995. Ovarian receptors for 17a, 20ß,21trihydroxy-4-pregnen-3-one (20ß-S) in striped bass. In: Goetz, F.W., Thomas, P., (Eds.), Reproductive Physiology of Fish, 1995. Fish Symposium 95, Austin, Texas, pp. 314. 


\section{Mylonas, Fostier and Zanuy}

Kinsey, W. H., Sharma, D., Kinsey, S. C., 2007. Fertilization and egg activation in fishes. In: Babin, P.J., Cerdá, J., Lubzens, E., (Eds.), The fish oocyte: From Basic Studies to Biotechnological Applications. Springer, The Netherlands, pp. 397-410.

Kishida, M., Anderson, T. R., Specker, J. L., 1992. Induction by ß-Estradiol of vitellogenin in striped bass (Morone saxatilis): characterization and quantification in plasma and mucus. Gen. Comp. Endocrinol. 88: 29-39.

Kjesbu, O. S., Kryvi, H., Norberg, B., 1996. Oocyte size and structure in relation to blood plasma steroid hormones in individually monitored, spawning Atlantic cod. J Fish Biol. 49: $1197-1215$.

Kobayashi, T., Pakarinen, P., Torgersen, J., Huhtaniemi, I., Anderson, O., 2008. The gonadotropin receptors FSH-R and LH-R of Atlantic halibut (Hippoglossus hypoglossus) - 2 . Differential follicle expression and asynchronous oogenesis. General and Comparative Endocrinology 156 : 595-602. Gen. Comp. Endocrinol. 156: 595-602.

Kumakura, N., Sakai, K., Takashima, F., 2003. Reproductive cycle and human chorionic gonadotropin-induced ovulation in hatchery reared Japanese catfish Silurus asotus. Fisheries Sci. 69: 495-504.

LaFleur, G. J., Thomas, P., 1991. Evidence for a role of $\mathrm{Na}^{+}, \mathrm{K}^{+}$-ATPase in the hydration of Atlantic croaker and spotted seatrout oocytes during final maturation. J. Exp. Zool. 258: 126136.

Lam, T. J., 1982. Applications of endocrinology to fish culture. Can. J. Aquat. Fish. Sci. 39: 11137.

Larsson, D. G. J., Mylonas, C. C., Zohar, Y., Crim, L. W., 1997. Gonadotropin releasing hormone-analogue (GnRH-A) advances ovulation and improves the reproductive 


\section{Broodstock management and hormonal manipulations of fish reproduction}

performance of a cold-water batch-spawning teleost, the yellowtail flounder (Pleuronectes ferrugineus). Can. J. Aquat. Fish. Sci. 54: 1957-1964.

Le Gac, F., Blaise, O., Fostier, A., Le Bail, P. Y., Loir, M., Mourot, B., Weil, C., 1993. Growth hormone (GH) and reproduction: a review. Fish Physiol. Biochem. 11: 219-232.

Le Menn, F., Cerdá, J., Babin, P. J., 2007. Ultrastructural aspects of the ontogeny and differentiation of ray-finned fish ovarian follicles. In: Babin, P.J., Cerdá, J., Lubzens, E., (Eds.), The Fish Oocyte: from Basic Studies to Biotechnological Applications. Kluwer Academic Publishers, Dordrecht, The Netherlands, pp. 1-37.

Lee, C.-S., Tamaru, C. S., Kelley, C. D., Moriwake, A., Miyamoto, G. T., 1992. The effect of salinity on the induction of spawning and fertilization in the striped mullet, Mugil cephalus. Aquaculture. 102: 289-296.

Lee, W.-K., Yang, S.-W., 2002. Relationship between ovarian development and serum levels of gonadal steroid hormones, and induction of oocyte maturation and ovulation in the cultured female Korean spotted sea bass Lateolabrax maculatus (Jeom-nong-eo). Aquaculture. 207:

Leonardo, A. F. G., Romagosa, E., Borella, M. I., Batlouni, S. R., 2004. Induced spawning of 169-183.

hatchery-raised Brazilian catfish, cachara Pseudoplatystoma fasciatum (Linnaeus, 1766). Aquaculture. 240: 451-461.

Lethimonier, C., Madigou, T., Munoz-Cueto, J.-A., Lareyre, J.-J., Kah, O., 2004. Evolutionary aspects of GnRHa, GnRH neuronal systems and GnRH receptors in teleost fish. Gen. Comp. Endocrinol. 135: 1-16.

Lim, H. K., Pankhurst, N. W., Fitzgibbon, Q. P., 2004. Effects of slow release gonadotropin releasing hormone analog on milt characteristics and plasma levels of gonadal steroids in greenback flounder Rhombosolea tapirina. Aquaculture. 240: 505-516. 


\section{Mylonas, Fostier and Zanuy}

1412

Linhart, O., Gela, D., Rodina, M., Kocour, M., 2004. Optimization of artificial propagation in European catfish, Silurus glanis L. Aquaculture. 235: 619-632.

Linhart, O., Kouril, J., Hamacková, J., 1987. Increase rate of egg fertilization in artificial propagation of sheatfish (Silurus glanis L.) by means of suppressing the movements of spermatozoa with immobilization solution. Aquaculture. 65: 353-358.

Liu, F.-G., Lin, T.-S., Huang, D.-U., Perng, M.-L., Liao, I. C., 2000. An automated system for egg collection, hatching, and transfer of larvae in a freshwater finfish hatchery. Aquaculture. 182: $137-148$.

Loir, M., Sourdaine, P., Mendis-Handagama, S. M., Jegou, B., 1995. Cell-cell interactions in the testis of teleosts and elasmobranchs. Microscopy Research And Technique. 32: 533-552.

Luckenbach, J. A., Iliev, D. B., Goetz, F. W., Swanson, P., 2008. Identification of differentially expressed ovarian genes during primary and early secondary oocyte growth in coho salmon, Oncorhynchus kisutch. Reproductive Biology and Endocrinology. 6: 2.

Ludwig, M., Felberbaum, R. E., Diedrich, K., Lunefeld, B., 2002. Ovarian stimulation: from basic science to clinical application. Reproductive Biomedicine Online. 5: 73-86.

Lutes, P. B., Doroshov, S. I., Chapman, F., Harrah, J., Fitzgerald, R., Fitzpatrick, M., 1987. Morpho-physiological predictors of ovulatory success in white sturgeon, Acipenser transmontanus Richardson. Aquaculture. 66: 43-52.

Malison, J. A., Procarione, L. S., Barry, T. P., Kapuscinski, A. R., Kayes, T. B., 1994. Endocrine and gonadal changes during the annual reproductive cycle of the freshwater teleost, Stizostedion vitreum. Fish Physiol. Biochem. 13: 473-484.

Malison, J. A., Procarione, L. S., Kayes, T. B., Hansen, J. F., Held, J. A., 1998. Induction of outof-season spawning in walleye (Stizostedion vitreum). Aquaculture. 163: 151-161. 


\section{Broodstock management and hormonal manipulations of fish reproduction}

Mañanos, E., Carrillo, M., Sorbera, L. S., Mylonas, C. C., Asturiano, J. F., Bayarri, M. J., Zohar, Y., Zanuy, S., 2002. Luteinizing hormone and sexual steroid plasma levels after treatment of European sea bass with sustained-release delivery systems for gonadotropin-releasing hormone analogue. J. Fish Biol. 60: 328-339.

Mañanos, E., Duncan, N., Mylonas, C. C., 2008. Reproduction and control of ovulation, spermation and spawning in cultured fish. In: Cabrita, E., Robles, V., Herráez, M.P., (Eds.), Methods in Reproductive Aquaculture: Marine and Freshwater Species. CRC Press, Taylor and Francis Group, Boca Raton, pp. 3-80.

Manning, A. J., Crim, L. W., 1998. Maternal and interannual comparison of the ovulatory periodicity, egg production and egg quality of the batch-spawning yellowtail flounder. J. Fish Biol. 53: 954-972.

Mansour, N., Lahnsteiner, F., Berger, B., 2003. Metabolism of intratesticular spermatozoa of a tropical telost fish (Clarias gariepinus). Comp. Biochem. Physiol. B135: 285-296.

Mansour, N., Lahnsteiner, F., Berger, B., 2004. Characterization of the testicular semen of the African catfish, Claria gariepinus (Burchell, 1822), and its short-term storage. Aqua. Res. 35: $232-244$.

Marino, G., Panini, E., Longobardi, A., Mandich, A., Finoia, M. G., Zohar, Y., Mylonas, C. C., 2003. Induction of ovulation in captive-reared dusky grouper, Epinephelus marginatus (Lowe, 1834) with a sustained-release GnRHa implant. Aquaculture. 219: 841-858.

Martínez-Pastor, F., Cabrita, E., Soares, F., Anel, L., Dinis, M. T., 2008. Multivariate cluster analysis to study motility activation of Solea senegalensis spermatozoa: a model for marine teleosts. Reproduction. 135: 449-459.

Masuma, S., 2006. Maturation and spawning of bluefin tuna in captivity. In: Sakamoto, W., Miyashita, S., Nakagawa, Y., (Eds.), Ecology and Aquaculture of Bluefin Tuna. Proceedings 


\section{Mylonas, Fostier and Zanuy}

of the Joint International Symposium on Bluefin Tuna, 2006. Fisheries Laboratory, Kinki University, Shirahama, Wakayam, Japan, pp. 15-20.

Mateos, J., Mananos, E., Martinez-Rodriguez, G., Carrillo, M., Querat, B., Zanuy, S., 2003. Molecular characterization of sea bass gonadotropin subunits $(\alpha, \mathrm{FSH} \beta$, and LHß) and their expression during the reproductive cycle. Gen. Comp. Endocrinol. 133: 216-232. V., Hara, A., 2003. Multiple vitellogenins and their unique roles in marine teleosts. Fish Physiol. Biochem. 28: 295-299.

Matsubara, T., Ohkubo, N., Andoh, T., Sullivan, C. V., Hara, A., 1999. Two forms of

Matsuyama, M., Chuda, H., Ikeda, Y., Tanaka, H., Matsuura, S., 1997. Induction of ovarian

Matsuyama, M., Takeuchi, H., Kashiwagi, M., Hirose, K., Kagawa, H., 1995. Induced gonadal development and spawning of immature red sea bream Pagrus major with LHRH-a administration in different ways during winter season. Fisheries Sci. 61: 472-477.

Meseda, M. E. G., Samira, S. A., 2006. Spawning induction in the Mediterranean mullet Mugil cephalus and larval developmental stages. African Journal of Biotechnology. 5: 1836-1845.

Mikolajczyk, T., Chyb, J., Sokolowska-Mikolajczyk, M., Enright, W. J., Epler, P., Filipiak, M., Breton, B., 2003. Attempts to induce an LH surge and ovulation in common carp (Cyprinus carpio L.) by differential application of a potent GnRH analogue, azagly-nafarelin, under laboratory, commercial hatchery, and natural conditions. Aquaculture. 223: 141-157. 


\section{Broodstock management and hormonal manipulations of fish reproduction}

Mikolajczyk, T., Chyb, J., Szczerbik, P., Sokolowska-Mikolajczyk, M., Epler, P., Enright, W. J., Filipiak, M., Breton, B., 2004. Evaluation of the potency of azagly-nafarelin (GnRH analogue), administered in combination with different formulations of pimozide, on LH secretion, ovulation and egg quality in common carp (Cyprinus carpio L.) under laboratory, commercial and natural conditions. Aquaculture. 234: 447-460.

Milla, S., Jalabert, B., Rime, H., Prunet, P., Bobe, J., 2006. Hydration of rainbow trout oocyte during meitoic maturation and in vitro regulation by 17,20beta-dihydroxy-4-pregne-3-one and cortisol. J. Exp. Biol. 209: 1147-1156.

Miranda, L. A., Cassará, M. C., Somoza, G. M. I. A. R., 2005. Increase in milt production by hormonal treatment in the pejerrey fish Odontesthes bonariensis (Valenciennes 1835). Aqua. Res. 36: 1473-1479.

Miura, T., Miura, C. I., 2003. Molecular control mechanisms of fish spermatogenesis. Fish Physiol. Biochem. 28: 181-186.

Miura, T., Yamauchi, K., Takahashi, H., Nagahama, Y., 1992. The role of hormones in the acquisition of sperm motility in salmonid fish. J. Exp. Zool. 261: 359-363.

Miwa, S., Yan, L., Swanson, P., 1994. Localization of two gonadotropin receptors in the salmon gonad by in vitro ligand autoradiography. Biol. Reprod. 50: 629-642.

Molés, G., Gómez, A., Rocha, A., Carrillo, A., Zanuy, S., 2008. Purification and characterization of follicle-stimulating hormone from pituitary glands of sea bass (Dicentrarchus labrax). Gen. Comp. Endocrinol. 158: 68-76.

Molony, B. W., Sheaves, M. J., 2001. Challenges of external insemination in a tropical sparid fish, Acanthopagrus berda. Env. Biol. Fish. 61: 65-71.

Montserrat, N., González, A., Méndez, E., Piferrer, F., Planas, J. V., 2004. Effects of follicle stimulating hormone on estradiol-17ß production and P-450 aromatase (CYP19) activity and 


\section{Mylonas, Fostier and Zanuy}

mRNA expression in brown trout vitellogenic ovarian follicles in vitro. Gen. Comp.

Moon, S. H., Lim, H. K., Kwon, J. Y., Lee, J. K., Chang, Y. J., 2003. Increased plasma 17hydroxyprogesterone and milt production in response to gonadotropin-releasing hormone analogue in captive male starry flounder, Platichthys stellatus. Aquaculture. 218: 703-716. on oocyte maturation, plasma sex steroid levels and egg production in female striped trumpeter Latris lineata (Latrididae). Aquaculture. 169: 315-331.

Mousa, S. A., Mousa, M. A., 2006. Involvement of corticotropin-releasing factor and adrenocorticotropic hormone in the ovarian maturation, seawater acclimation, and induced spawning of Liza ramada. Gen. Comp. Endocrinol. 146: 167-179.

Mugnier, C., Fostier, A., Guezou, S., Gaignon, J. L., Quemener, L., 1998. Effect of some repetitive factors on turbot stress response. Aquacult. Int. 6: 33-45.

Mugnier, C., Gaignon, J. L., Lebegue, E., Fostier, A., Breton, B., 2000. Induction and synchronisation of spawning in cultivated turbot (Scophthalmus maximus L.) broodstock by implantation of sustained-release GnRH-a pellet. Aquaculture. 181: 241-255.

Mylonas, C. C., Bridges, C. R., Gordin, H., Belmonte Ríos, A., García, A., De la Gándara, F., Fauvel, C., Suquet, M., Medina, A., Papadaki, M., Heinisch, G., De Metrio, G., Corriero, A., Vassallo-Agius, R., Guzmán, J. M., Mañanos, E., Zohar, Y., 2007. Preparation and administration of gonadotropin-releasing hormone agonist (GnRHa) implants for the artificial control of reproductive maturation in captive-reared Atlantic bluefin tuna (Thunnus thynnus thynnus). Reviews in Fisheries Science. 15: 183-210.

Mylonas, C. C., Hinshaw, J. M., Sullivan, C. V., 1992. GnRHa-induced ovulation of brown trout (Salmo trutta) and its effects on egg quality. Aquaculture. 106: 379-392. 


\section{Broodstock management and hormonal manipulations of fish reproduction}

Mylonas, C. C., Kyriakou, G., Sigelaki, I., Georgiou, G., Stephanou, D., Divanach, P., 2004a.

Reproductive biology of the shi drum (Umbrina cirrosa) in captivity and induction of spawning using GnRHa. Isr. J. Aquacult.-Bamidgeh. 56: 75-92.

Mylonas, C. C., Magnus, Y., Gissis, A., Klebanov, Y., Zohar, Y., 1996. Application of controlled-release, GnRHa-delivery systems in commercial production of white bass x striped bass hybrids (sunshine bass), using captive broodstocks. Aquaculture. 140: 265-280.

Mylonas, C. C., Magnus, Y., Gissis, A., Klebanov, Y., Zohar, Y., 1997a. Reproductive biology and endocrine regulation of final oocyte maturation of captive white bass. J. Fish Biol. 51: 234-250.

Mylonas, C. C., Papadaki, M., Divanach, P., 2003a. Seasonal changes in sperm production and quality in the red porgy Pagrus pagrus (L.). Aqua. Res. 34: 1161-1170.

Mylonas, C. C., Papadaki, M., Pavlidis, M., Divanach, P., 2004b. Evaluation of egg production and quality in the Mediterranean red porgy (Pagrus pagrus) during two consecutive spawning seasons. Aquaculture. 232: 637-649.

Mylonas, C. C., Papandroulakis, N., Smboukis, A., Papadaki, M., Divanach, P., 2004c. Induction of spawning of cultured greater amberjack (Seriola dumerili) using GnRHa implants. Aquaculture. 237: 141-154.

Mylonas, C. C., Scott, A. P., Vermeirssen, E. L. M., Zohar, Y., 1997b. Changes in plasma gonadotropin II and sex steroid hormones, and sperm production of striped bass after treatment with controlled-release gonadotropin-releasing hormone agonist-delivery systems. Biol. Reprod. 57: 669-675.

Mylonas, C. C., Scott, A. P., Zohar, Y., 1997c. Plasma gonadotropin II, sex steroids, and thyroid hormones in wild striped bass (Morone saxatilis) during spermiation and final oocyte maturation. Gen. Comp. Endocrinol. 108: 223-236. 


\section{Mylonas, Fostier and Zanuy}

Mylonas, C. C., Sigelaki, I., Divanach, P., Mañanos, E., Carillo, M., Afonso-Polyviou, A., 2003b. Multiple spawning and egg quality of individual European sea bass (Dicentrarchus labrax) females after repeated injections of GnRHa. Aquaculture. 221: 605-620.

Mylonas, C. C., Tabata, Y., Langer, R., Zohar, Y., 1995a. Preparation and evaluation of polyanhydride microspheres containing gonadotropin-releasing hormone $(\mathrm{GnRH})$, for inducing ovulation and spermiation in fish. J. Control. Release. 35: 23-34.

Mylonas, C. C., Woods, L. C., III, Thomas, P., Schulz, R. W., Zohar, Y., 1998a. Hormone profiles of captive striped bass (Morone saxatilis) during spermiation, and long-term enhancement of milt production. J. World Aquac. Soc. 29: 379-392.

Mylonas, C. C., Woods, L. C., III, Thomas, P., Zohar, Y., 1998b, Endocrine profiles of female striped bass (Morone saxatilis) in captivity, during post-vitellogenesis and induction of final oocyte maturation via controlled-release GnRHa-delivery systems. Gen. Comp. Endocrinol. 110: 276-289.

Mylonas, C. C., Woods, L. C., III, Zohar, Y., 1997d. Cyto-histological examination of postvitellogenesis and final oocyte maturation in captive-reared striped bass. J. Fish Biol. 50: 3449.

Mylonas, C. C., Zohar, Y., 2001a. Endocrine regulation and artificial induction of oocyte maturation and spermiation in basses of the genus Morone. Aquaculture. 202: 205-220.

Mylonas, C. C., Zohar, Y., 2001b. Use of GnRHa-delivery systems for the control of reproduction in fish. Rev. Fish Biol. Fish. 10: 463-491.

Mylonas, C. C., Zohar, Y., 2007. Promoting oocyte maturation, ovulation and spawning in farmed fish. In: Babin, P.J., Cerdá, J., Lubzens, E., (Eds.), The Fish Oocyte: from Basic Studies to Biotechnological Applications. Kluwer Academic Publishers, Dordrecht, The Netherlands, pp. 433-470. 


\section{Broodstock management and hormonal manipulations of fish reproduction}

Mylonas, C. C., Zohar, Y., Richardson, B. M., Minkinnen, S. P., 1995b. Induced spawning of wild American shad, Alosa sapidissima, using sustained administration of gonadotropinreleasing hormone analog (GnRHa). J. World Aquac. Soc. 26: 240-251.

Nagahama, Y., Yoshikuni, M., Yamashita, M., Tanaka, M., 1994. Regulation of oocyte maturation in fish. In: Sherwood, N.M., Hew, C.L., (Eds.), Fish Physiology. Academic Press, San Diego, California, pp. 393-439.

Negatu, Z., Hsiao, S. M., Wallace, R. A., 1998. Effects of insulin-like growth factor-I on final oocyte maturation and steroid production in Fundulus heteroclitus. Fish Physiol. Biochem. 19: $13-21$.

Ohta, H., Kagawa, H., Tanaka, H., Okuzawa, K., Hirose, K., 1996. Changes in fertilization and hatching rates with time after ovulation induced by 17,20ß-dihydroxy-4-pregnen-3-one in the Japanese eel, Anguilla japonica. Aquaculture. 139: 291-301.

Ohta, H., Tanaka, H., 1997. Relationship between serum levels of human chorionic gonadotropin (hCG) and 11-ketotestosterone after a single injection of hCG and induced maturity in the male Japanes eel, Anguilla japonica. Aquaculture. 153: 123-134.

Okumura, S., Okamoto, K., Oomori, R., H., S., Nakazono, A., 2003. Improved fertilization rates by using a large volume spawning tank in red spotted grouper (Epinephelus akaara). Fish Physiol. Biochem. 28: 515-516.

Okumura, S., Okamoto, K., Oomori, R., Nakazono, A., 2002. Spawning behavior and artificial fertilization in captive reared red spotted grouper, Epinephelus akaara. Aquaculture. 206: 165-173.

Ottolenghi, F., Silvestri, C., Giordano, P., Lovatelli, A., New, M. B., 2004. Capture-based Aquaculture. The fattening of eels, groupers, tunas and yellowtails. Food and Agriculture Organization of the United Nations, Rome. 


\section{Mylonas, Fostier and Zanuy}

Palstra, A. P., Cohen, E. G. H., Niemantsverdriet, P. R. W., van Ginneken, V. J. T., van den Thillart, G. E. E. J. M., 2005. Artificial maturation and reproduction of European silver eel: development of oocytes during final maturation. Aquaculture. 249: 533-547.

Pankhurst, N. W., Fitzgibbon, Q. P., 2006. Characteristics of spawning behaviour in cultured greenback flounder, Rhombosa tapirina. Aquacultrue. 253: 279-289.

Pankhurst, N. W., Purser, G. J., Van Der Kraak, G., Thomas, P. M., Forteath, G. N. R., 1996. Effect of holding temperature on ovulation, egg fertility, plasma levels of reproductive hormones and in vitro ovarian steroidogenesis in the rainbow trout Oncorhynchus mykiss. Aquaculture. 146: 277-290.

Pankhurst, N. W., Thomas, P. M., 1998. Maintenance at elevated temperature delays the steroidogenic and ovulatory responsiveness of rainbow trout Oncorhynchus mykiss to luteinizing hormone releasing hormone analogue. Aquaculture. 166: 163-177.

Papadaki, M., Papadopoulou, M., Sigelaki, I., Mylonas, C. C., 2008. Egg and sperm production and quality of sharpsnout sea bream (Diplodus puntazzo) in captivity. Aquaculture. 276: 187197.

Papanikos, N., Phelps, R. P., Williams, K., Ferry, A., Maus, D., 2003. Egg and larval quality of natural and induced spawns of red snapper, Lutjanus campechanus Fish Physiol. Biochem.

$$
\text { 28: } 487-488 \text {. }
$$

Park, I. S., Choi, G. C., Nam, Y. K., Kim, D. S., 2002. The effect of exogenous hormone treatment on spermiation in Rhynchocypris oxycephalus (Sauvage and Dabry). J. World Aquac. Soc. 33: 494-500.

Paspatis, M., Markakis, G., Koumoundouros, G., Kentouri, M., 1999. Preliminary results on rearing of Sparus Aurata $\times$ Pagrus Pagrus hybrids. Performance comparison with the parental species. Aquacult. Int. 7: 29-44. 


\section{Broodstock management and hormonal manipulations of fish reproduction}

Patiño, R., Sullivan, C. V., 2002. Ovarian follicle growth, maturation, and ovulation in teleost fish. Fish Physiol. Biochem. 26: 57-70.

Patiño, R., Yoshizaki, G., Thomas, P., Kagawa, H., 2001. Gonadotropic control of ovarian follicle maturation: the two-stage concept and its mechanisms. Comp. Biochem. Physiol. B129: 427-439.

Pavlidis, M., Greenwood, L., Scott, A. P., 2004. The role of sex ratio on spawning performance and on the free and conjugated sex steroids released into the water by common dentex (Dentex dentex) broodstock. Gen. Comp. Endocrinol. 138: 255-262.

Peter, R. E., Yu, K. L., 1997. Neuroendocrine regulation of ovulation in fishes: basic and applied aspects. Rev. Fish Biol. Fish. 7: 173-197.

Petersson, J., Järvi, T., 2001. 'False orgasm' in female brown trout: trick or treat? Anim. Behav. 61: 497-501.

Piper, R. G., McElwain, I. B., Orme, L. E., McCraren, J. P., Fowler, L. G., Leonard, J. R., 1982. Fish Hatchery Management. Washington, D.C.

Polzonetti-Magni, A., Mosconi, G., Soverchia, L., Kikuyama, S., Carnevali, O., 2004.

Multihormonal control of vitellogenesis in lower vertebrates. Int. Rev. Cytol. 239: 1-45.

Poortenaar, C. W., Pankhurst, N. W., 2000. Effect of luteinising hormone-releasing hormone analogue and human chorionic gonadotropin on ovulation, plasma and ovarian levels of gonadal steroids in greenback flounder Rhombosolea tapirina. J. World Aquac. Soc. 31: 175-

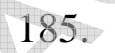

Pudney, J., 1995. Spermatogenesis in nonmammalian vertebrates. Microscopy Research And Technique. 32: 459-497. 


\section{Mylonas, Fostier and Zanuy}

Rainis, S., Mylonas, C. C., Kyriakou, Y., Divanach, P., 2003. Enhancement of spermiation in European sea bass (Dicentrarchus labrax) at the end of the reproductive season using GnRHa implants. Aquaculture. 219: 873-890.

Rocha, A., Zanuy, S., Carrillo, M., Gómez, A., 2008. Seasonal changes in gonadal expression of gonadotropin receptors, steroidogenic acute regulatory protein and steroidogenic enzymes in the European sea bass. J. Endocrinol. 000: 000-000.

Rodríguez, R., Celada, J. D., Saez-Royuela, M., Carral, J. M., Aquilera, A., Melendre, P. M., 2004. Artificial reproduction in 1-year-old tench (Tinca tinca L.). J. Appl. Ichthyol. 20: 542544.

Rosenfeld, H., Meiri, I., Elizur, A., 2007. Gonadotropin regulation of oocyte development. In: Babin, P.J., Cerdá, J., Lubzens, E., (Eds.), The Fish Oocyte: from Basic Studies to Biotechnological Applications. Kluwer Academic Publishers, Dordrecht, The Netherlands, pp. 171-198.

Rudolfsen, G., Figenschou, L., Folstad, I., Kleven, O., 2008. Sperm velocity influences paternity in the Atlantic cod (Gadus morhua L.). Aqua. Res. 39: 212-216.

Rurangwa, E., Kime, D. E., Ollevier, F., Nash, J. P., 2004. The measurement of sperm motility and factors affecting sperm quality in cultured fish. Aquaculture. 234: 1-28.

Rzemieniecki, A., Domagala, J., Glogowski, J., Ciereszko, A., Trzebiatowski, R., Kouril, J., Hamackova, J., Babiak, I., 2004. Induced spermiation in 3-year-old sterlet, Acipenser ruthenus L. Aqua. Res. 35: 144-151.

Saito, K., O'Donnell, L., McLachlan, R. I., Robertson, D. M., 2000. Spermiation failure is a major contributor to early spermatogenic suppression caused by hormone withdrawal in adult rats. Endocrinol. 141: 2779-2785. 


\section{Broodstock management and hormonal manipulations of fish reproduction}

1672

1674

1676

Sakai, K., Nomura, M., Takashima, F., Oto, H., 1975. The over-ripening phenomenon of rainbow trout-II changes in the percentage of eyed eggs, hatching rate and incidence of abnormal alevins during the process of over-ripening. Bull. Jap. Soc. Sci. Fish. 41: 855-860.

Sato, N., Kawazoe, I., Shiina, Y., Furukawa, K., Suzuki, Y., Aida, K., 1995. A novel method of hormone administration for inducing gonadal maturation in fish. Aquaculture. 135: 51-58.

Sawada, Y., Okada, T., Miyashita, S., Murata, O., Kumai, H., 2005. Completion of the Pacific bluefin tuna Thunnus orientalis (Temmich et Schlegel) life cycle. Aqua. Res. 36: 413-421.

Sawaguchi, S., Kagawa, H., Ohkubo, N., Hiramatsu, K., Sullivan, C. V., Matsubara, M., 2006. Molecular characterization of three forms of vitellogenin and their yolk protein products during oocyte growth and maturation in red seabream (Pagrus major), a marine teleost spawning pelagic eggs. Mol. Repro. Dev. 73: 719-736.

Schally, A. V., 1978. Aspects of hypothalamic regulation of the pituitary gland. Science. 202:

$$
18-28 .
$$

Schiavone, R., Zilli, L., Vilella, S., Fauvel, C., 2006. Human chorionic gonadotropin induces spermatogenesis and spermiation in 1-year-old European sea bass (Dicentrarchus labrax): assessment of sperm quality. Aquaculture. 255: 522-531.

Schulz, D. R., Perez, N., Tan, C.-K., Mendez, A. J., Capo, T. R., Snodgrass, D., Prince, E. D., Serafy, J. E., 2005a. Concurrent levels of 11-ketotestosterone in fish surface mucus, muscle tissue and blood. J. Appl. Ichthyol. 21: 394-398.

Schulz, R. W., Miura, T., 2002. Spermatogenesis and its endocrine regulation. Fish Physiol. Biochem. 26: 43-56.

Schulz, R. W., Sandra Menting, S., Bogerd, J., França, L. R., Vilela, D. A. R., Godinho, H. P., 2005b. Sertoli cell proliferation in the adult testis_Evidence from two fish species belonging to different orders. Biol. Reprod. 73: 891-898. 


\section{Mylonas, Fostier and Zanuy}

1696

1698

1700

Scott, A. P., Baynes, S. M., 1980. A review of the biology, handling and storage of salmonid spermatozoa. J. Fish Biol. 17: 707-739.

Shiraishi, T., Ohta, K., Yamaguchi, A., Yoda, M., Chuda, H., Matsuyama, M., 2005.

Reproductive parameters of the chub mackerel Scomber japonicus estimated from human chorionic gonadotropin-induced final oocyte maturation and ovulation in captivity. Fisheries Sci. 71: 531-542.

Silverstein, J. T., Bosworth, B. G., Wolters, W. R., 1999. Evaluation of dual injection of LHRHa and the dopamine receptor antagonist pimozide in cage spawning of channel catfish Ictalurus punctatus. J. World Aquac. Soc. 30: 263-268.

Slater, C., Schreck, C. B., Swanson, P., 1994. Plasma profiles of the sex steroids and gonadotropins in maturing female spring chinook salmon (Oncorhynchus tshawytscha). Comp. Biochem. Physiol. 109A: 167-175.

Slater, C. H., Schreck, C. B., Amend, D. F., 1995. GnRHa injection accelerates final maturation and ovulation/spermiation of sockeye salmon (Oncorhynchus nerka) in both fresh and salt water. Aquaculture. 130: 279-285.

Solar, I. I., Smith, J., Dye, H. M., MacKinlay, D. D., Zohar, Y., Donaldson, E. M., 1995. Induced ovulation of chinook salmon using a GnRHa implant: effect on spawning, egg viability and hormone levels. In: Goetz, F.W., Thomas, P., (Eds.), Reproductive Physiology of Fish. Fish Symposium 95, Austin, Texas, pp. 144.

Sorbera, L. A., Asturiano, J. F., Carrillo, M., Cerda, J., Kime, D. E., Zanuy, S., 1999. In vitro maturation in the sea bass: effects of hCG, pituitary extract and steroids. J. Fish Biol. 55: 925. 


\section{Broodstock management and hormonal manipulations of fish reproduction}

1718

Sorbera, L. A., Mylonas, C. C., Zanuy, S., Carillo, M., Zohar, Y., 1996. Sustained administration of GnRHa increases milt volume without altering sperm counts in the sea bass. J. Exp. Zool. 276: 361-368.

Sower, S., Shreck, C., 1982. Steroid and thyroid hormones during sexual maturation of coho salmon (Oncorhynchus kisutch) in seawater or fresh water. Gen. Comp. Endocrinol. 47:4253.

Springate, J. R. C., Bromage, N. R., Elliot, J. A. K., Hudson, D. L., 1984. The timing of ovulation and stripping and their effects on the rates of fertilization and survival to eyeing, hatch and swim-up in the rainbow trout (Salmo gairdneri). Aquaculture. 43: 313-322.

Stacey, N., 2003. Hormones, pheromones and reproductive behavior. Fish Physiol. Biochem. 28: 229-235.

Steven, C., Studies on the GnRH-GtH system of female striped bass (Morone saxatilis): effects of GnRH agonist therapy and comparison of reproductive endocrine parameters between wild and captive fish. Marine Estuarine and Environmental Sciences. Univeristy of Maryland, College Park, 2000.

Steven, C., Gothilf, Y., Holland, M. C. H., Stubblefield, J., Mylonas, C. C., Zohar, Y., 2000. Differential expression of the three GnRH genes in wild and captive striped bass, Morone saxatilis, in response to natural and hormonally induced maturation. In: Norberg, B., Kjesbu, O.S., Taranger, G.L., Andersson, E., Stefansson, S.O., (Eds.), Reproductive Physiology of Fish. University of Bergen, Bergen, pp. 66.

Stoltz, J. A., Neff, B. D., 2006. Sperm competition in a fish with external fertilization: the contribution of sperm number, speed and length. J. Evol. Biol. 19: 1873-1881. 


\section{Mylonas, Fostier and Zanuy}

Sullivan, C. V., Bernard, M. G., Hara, A., Dickhoff, W. W., 1989. Thyroid hormones in trout reproduction: enhancement of GnRHa and partially purified salmon GtH-induced ovarian maturation in vivo and in vitro. J. Exp. Zool. 250: 188-195.

Suquet, M., Billard, R., Cosson, J., Dorange, G., Chauvaud, L., Mugnier, C., Fauvel, C., 1994. Sperm features in turbot (Scophthalmus maximus): a comparison with other freshwater and marine fish species. Aquat. Living Resour. 7: 283-294.

Suquet, M., Billard, R., Cosson, J., Normant, Y., Fauvel, C., 1995. Artificial insemination in turbot (Scophthalmus maximus): determination of the optimal sperm to egg ratio and time of gamete contact. Aquaculture. 133: 83-90.

Suwa, K., Yamashita, M., 2007. Regulatory mechanisms of oocyte maturation and ovulation. In: Babin, P.J., Cerdá, J., Lubzens, E., (Eds.), The Fish Oocyte: from Basic Studies to Biotechnological Applications. Kluwer Academic Publishers, Dordrecht, The Netherlands. Szabó, T., 2001. Hormonally induced ovulation of northern pike via sustained-release vehicles. North American Journal of Aquaculture. 63: 137-143.

Takashima, F., Weil, C., Billard, R., Crim, L. W., Fostier, A., 1984. Stimulation of spermiation by LHRH analogue in carp. Bull. Jap. Soc. Sci. Fish. 50: 1323-1329.

Takushima, M., Nozaki, R., Kadomura, K., Yasumoto, S., Soyano, K., 2003. Induced ovulation using LHRHa and artificial fertilization in devil stinger, Inimicus japonicus. Fish Physiol. Biochem. 28: 521-522.

Thomas, P., Arnold, C. R., Holt, G. J., 1995. Red drum and other sciaenids. In: Bromage, N.R., Roberts, R.J., (Eds.), Broodstock Management and Egg and Larval Quality. Blackwell Science, Oxford, pp. 118-137. 


\section{Broodstock management and hormonal manipulations of fish reproduction}

Tsadik, G. G., Bart, A. N., 2007. Effects of feeding, stocking density and water-flow rate on fecundity, spawning frequency and egg quality of Nile tilapia, Oreochromis niloticus (L.). Aquacultrue. 272: 380-388.

Tucker, J. W., 1994. Spawning of captive serranid fishes: a review. J. World Aquac. Soc. 25. $345-359$.

Tveiten, H., Solevac, S. E., Johnsen, H. K., 2001. Holding temperature during the breeding season influences final maturation and egg quality in common wolffish. J. Fish Biol. 58: 374385.

Tyler, J. R., Sumpter, J. P., 1996. Oocyte growth and development in teleosts. Rev. Fish Biol. Fish. 6: 287-318.

Uchida, K., Kaneko, T., Yamaguchi, A., Ogasawara, Y., Hirano, T., 1997. Reduced hypoosmoregulatory ability and alteration in gill chloride distribution in mature chum salmon (Oncorhynchus keta) migrating upstream for spawning. Mar. Biol. 129: 247-253.

Ulloa-Aguirre, A., Timossi, C., 2000. Biochemical and functional aspects of gonadotrophinreleasing hormone and gonadotrpophins. Reproductive Biomedicine Online. 1: 48-62.

Unuma, T., Kondo, S., Tanaka, H., Kagawa, H., Nomura, K., Ohta, H., 2005. Relationship between egg specific gravity and egg quality in the Japanese eel, Anguilla japonica. Aquaculture. 246: 493-500.

Van Der Kraak, G., Dye, H. M., Donaldson, E. M., Hunter, G. A., 1985. Plasma gonadotropin, 17ß-estradiol, and 17 ,20ß-dihydroxy-4-pregnen-3-one levels during luteinizing hormonereleasing hormone analogue and gonadotropin induced ovulation in coho salmon (Oncorhynchus kisutch). Can. J. Zool. 63: 824-833. 


\section{Mylonas, Fostier and Zanuy}

1784

1786

Van Der Kraak, G., Pankhurst, N. W., 1996. Temperature effects on the reproductive performance of fish. In: Wood, C.M., McDonald, D.G., (Eds.), Global Warming: Implications for Freswater and Marine Fish. Cambridge University Press, Cambridge, pp. 159-176.

van Ginneken, V. J. T., Maes, G. E., 2005. The European eel (Anguilla anguilla, Linnaeus), its lifecycle, evolution and reproduction: a literature review. Rev. Fish Biol. Fish. 15: 367-398.

Vermeirssen, E. L. M., Mazorra de Quero, C., Shields, R. J., Norberg, B., Kime, D. E., Scott, A. P., 2003. Fertility and motility of sperm from Atlantic halibut (Hippoglossus hippoglossus) in relation to dose and timing of gonadotropin-releasing hormone agonist implant. Aquaculture. 230: 547-567.

Vermeirssen, E. L. M., Scott, A. P., Mylonas, C. C., Zohar, Y., 1998. Gonadotrophin-releasing hormone agonist stimulates milt fluidity and plasma concentrations of 17,20ß-dihydroxylated and 5ß-reduced, 3a-hydroxylated C21 steroids in male plaice (Pleuronectes platessa). Gen. Comp. Endocrinol. 112: 163-177.

Vermeirssen, E. L. M., Shields, R. J., Mazorra de Quero, C., Scott, A. P., 2000. Gonadotrophinreleasing hormone agonist raises plasma concentrations of progestogens and enhances milt fluidity in male Atlantic halibut (Hippoglossus hippoglossus). Fish Physiol. Biochem. 22: 77 87.

Viveiros, A. T. M., Eding, E. H., Komen, J., 2001. Effects of $17 \alpha$-methyltestosterone on seminal vesicle development and semen release response in the African catfish, Clarias gariepinus. Reproduction. 122: 817-827.

Viveiros, A. T. M., Fessehaye, Y., ter Veld, M., Schulz, R. W., Komen, J., 2002. Hand-stripping of semen and semen quality after maturational hormone treatments, in African catfish Clarias gariepinus. Aquaculture. 213: 373-386. 


\section{Broodstock management and hormonal manipulations of fish reproduction}

Vizziano, D., Fostier, A., Loir, M., Le Gac, F., 2008. Testis development, its hormonal regulation and spermiation induction in teleost fish. In: Alavi, S.M.H., Cosson, J., Coward, K., Rafiee, G., (Eds.), Fish Spermatology. Alpha Science Intl, Oxford (UK), pp. 103-139.

Von Ihering, R., 1937. A method for inducing spawning in fish. Prog. Fish-Cult. 34: 15-16.

Watanabe, A., Onitake, K., 2008. The regulation of spermatogenesis in fish: recent cellular and molecular approaches. In: Alavi, S.M.H., Cosson, J., Coward, K., Rafiee, G., (Eds.), Fish Spermatology. Alpha Science Intl, Oxford (UK), pp. 141-160.

Watanabe, T., Kiron, V., 1995. Red sea bream (Pagrus major). In: Bromage, N.R., Roberts, R.J., (Eds.), Broodstock Management and Egg and Larval Quality. Blackwell Science, Oxford, pp. 398-413.

Watanabe, W. O., Carroll, P. M., Daniels, H. V., 2001. Sustained, natural spawning of southern flounder Paralichthys lethostigma under an extended photothermal regime. J. World Aquac. Soc. 32: 153-166.

Watanabe, W. O., Ellis, E. P., Ellis, S. C., Feeley, M. W., 1998. Progress in controlled maturation and spawning of summer flounder (Paralichthys dentatus) broodstock. J. World Aquac. Soc. 29: 393-404.

Watanabe, W. O., Smith, T. I. J., Berlinsky, D. L., Woolridge, C. A., Stuart, K. R., Copeland, K. A., Denson, M. R., 2003. Volitional spawning of black sea bass Centropristis striata induced with pelleted luteinizing hormone releasing hormone-analogue. J. World Aquac. Soc. 34: $319-331$.

Webb, M. A. H., Van Eenennaam, J. P., Doroshov, S. I., Moberg, G. P., 1999. Preliminary observations on the effects of holding temperature on reproductive performance of female white sturgeon, Acipenser transmontanus Richardson. Aquaculture. 176: 315-329. 


\section{Mylonas, Fostier and Zanuy}

1830

Weber, G. M., Borski, R. J., Powell, J. F. F., Sherwood, N. M., Grau, E. G., 1995. In vivo and in vitro effects of gonadotropin-releasing hormone on prolactin in the tilapia Oreochromis mossambicus. American Zoologist (Abstract). 34:121A.

Weil, C., Crim, L. W., 1983. Administration of LHRH analogues in various ways: effect on the advancement of spermiation in prespawning landlocked salmon, Salmo salar. Aquaculture. 35: 103-115.

Wen, H. S., Lin, H. R., 2004. Effects of exogenous neurohormone, gonadotropin (GtH) and dopaminergic drugs on the serum GtH content and ovulatory responsiveness of wild catfish, Silurus asorus (Linnaeus, 1758). Aqua. Res. 35: 204-212.

Wendling, N. C., Bencic, D. C., Nagler, J. J., Cloud, J. G., Ingermann, R. L., 2000. Adenosine triphosphate levels of chinook salmon (Oncorhynchus tshawytscha) eggs following in vitro maintenance and activation/fertilization. Fish Physiol. Biochem. 22: 217-223.

Wexler, J. B., Scholey, V. P., Olson, R. J., Margulies, D., Nakazawa, A., Suter, J. M., 2003. Tank culture of yellowfin tuna, Thunnus albacares: developing a spawning population for research purposes. Aquacuiture. 220: 327-353.

Williot, P., Brun, R., Rouault, T., Pelard, M., Mercier, D., Ludwig, A., 2005. Artificial spawning in cultured sterlet sturgeon, Acipenser ruthenus L., with special emphasis on hermaphrodites. Aquaculture. 246: 263-273.

Williot, P., Brun, R., Rouault, T., Rooryck, O., 1991. Management of female breeders of the Siberia sturgeon, Acipenser baeri Brandt: first results. In: Williot, P., (Ed.), Acipenser. Cemagref Publications, France, pp. 365-379.

Williot, P., Gulyas, T., Ceapa, C., 2002. An analogue of GnRH is effective for induction of ovulation and spermiation in farmed Siberian sturgeon Acipenser baerii Brandt. Aqua. Res. 33: $735-737$. 


\section{Broodstock management and hormonal manipulations of fish reproduction}

1854

1856

1858

Williot, P., Sabeau, L., Gessner, J., Arlati, G., Bronzi, P., Gulyas, T., Berni, P., 2001. Sturgeon farming in Western Europe: recent developments and perspectives. Aquat. Living Resour. 14: $367-374$.

Woolsey, J., Ingermann, R. L., 2003. Acquisition of the potential for sperm motility in steelhead (Oncorhynchus mykiss): effect of pH on dynein ATPase. Fish Physiol. Biochem. 29: 47-56.

Yang, Z., Chen, Y.-F., 2004. Induced ovulation in obscure puffer Takifugu obscurus by injections of LHRH-a. Aquacult. Int. 12: 215-223.

Yaron, Z., 1995. Endocrine control of gametogenesis and spawning induction in the carp. Aquaculture. 129: 49-73.

Yu, K. L., Lin, X. W., da Cunha Bastos, J., Peter, R. E., 1997. Neural regulation of GnRH in teleost fishes. In: Parhar, I.S., Sakuma, Y., (Eds.), GnRH Neurons: Gene to Behavior. Brain Shuppan, Tokyo, pp. 277-312.

Zakes, Z., Szczepkowski, M., 2004. Induction of out-of-season spawning of pikeperch, Sander lucioperca (L.). Aquacult. Int. 12: 11-18.

Zhuang, P., Kynard, B., Zhang, L., Zhang, T., Zhang, Z., Li, D., 2002. Overview of biology and aquaculture of Amur sturgeon (Acipenser schrenckii) in China. J. Appl. Ichthyol. 18: 659664.

Zohar, Y., 1988. Gonadotropin releasing hormone in spawning induction in teleosts: basic and applied considerations. In: Zohar, Y., Breton, B., (Eds.), Reproduction in Fish: Basic and Applied Aspects in Endocrinology and Genetics. INRA Press, Paris, pp. 47-62.

Zohar, Y., 1989. Fish reproduction: its physiology and artificial manipulation. In: Shilo, M., Sarig, S., (Eds.), Fish Culture in Warm Water Systems: Problems and Trends. CRC Press, Boca Raton, pp. 65-119. 


\section{Mylonas, Fostier and Zanuy}

Zohar, Y., 1996. New approaches for the manipulation of ovulation and spawning in farmed fish. Bull. Natl. Res. Inst. Aquacult., Suppl. 2: 43-48.

Zohar, Y., Harel, M., Hassin, S., Tandler, A., 1995. Gilthead sea bream (Sparus aurata). In: Bromage, N.R., Roberts, R.J., (Eds.), Broodstock Management and Egg and Larval Quality. Blackwell Science, Oxford, pp. 94-117.

Zohar, Y., Mylonas, C. C., 2001a. Endocrine manipulations of spawning in cultured fish: from hormones to genes. Aquaculture. 197: 99-136.

Zohar, Y., Mylonas, C. C., 2001b. Endocrine manipulations of spawning in cultured fish: from hormones to genes. In: Donaldson, E.M., Lee, C.S., (Eds.), Reproductive Biotechnology in 


\section{Broodstock management and hormonal manipulations of fish reproduction}

1890

1894

1896

1898

1900

1902

\section{FIGURE LEGENDS}

Figure 1. Schematic representation of the reproductive axis in fish, its major components and phases, and its environmental and endocrine control.

Figure 2. Microphotographs of histological sections from testes of European sea bass at various stages of maturation. (A) Before the onset of the reproductive season, containing only spermatogonia (sg). (B) At the early stage of spermatogenesis in November, containing spermatocysts with spermatocytes I and II (sc) and spermatids (st), including some spermatozoa (sz). (C) In December when spermiation begins, showing the extensive rupture of the mature spermatocysts and the aggregation of spermatozoa in the tubules. (D) In January at the onset of the females spawning season, with the tubules containing almost exclusively spermatozoa. The bar at the bottom of each photograph is $200 \mu \mathrm{m}$.

Figure 3. Microphotographs of histological sections from ovaries of (A) striped bass, a synchronous fish having all oocytes at the same stage of maturation (lipid droplet coalescence, germinal vesicle migration), and (B) Atlantic bluefin tuna, an asynchronous fish having oocytes at different stages of vitellogenesis (cortical alveoli, early and late vitellogenesis). gv = germinal vesicle, $\mathrm{ld}=$ lipid droplets, $\mathrm{y}=$ yolk vesicles, $\mathrm{Ca}=$ cortical alveoli stage, Evg $=$ early vitellogenesis stage, $\mathrm{Lvg}=$ late vitellogenesis stage. The bar at the bottom of each photograph is $200 \mu \mathrm{m}$.

Figure 4. The process of oocyte maturation $(\mathrm{OM})$ in European sea bass. (A) Time course of in vitro $\mathrm{OM}(\%)$ induced by graded doses of the two maturation inducing steroids $(17,20 ß \mathrm{P}$ and 20ßS) and hCG (which has LH-like activity). (B) Mean ( \pm SEM) plasma levels of 17,20ßP and 


\section{Mylonas, Fostier and Zanuy}

1914

1916

1918

20ßS in relation to the oocyte stage of development of the most advanced oocytes. The data was compiled from individual females ( $\mathrm{n}$ in parentheses) in several samplings, independent of the time of sampling. PREVTG = pre-vitellogenesis, eVtG = early vitellogenesis, $\mathrm{aVTG}=$ advanced vitellogenesis, POSTVTG $=$ post-vitellogenesis, eMAT $=$ early $\mathrm{OM}$, fMAT $=$ final OM, OVUL = ovulation, ATRE $=$ atresia. Different letters superscripts indicate significant differences (ANOVA, DNMR, $P<0.05$ ). (Modified from Asturiano et al., 2000, Sorbera et al., 1999).

Figure 5. Photographs of milt collection from a wreckfish (Polyprion americanus) after abdominal pressure (A) and acquisition of an ovarian biopsy using a catheter (B).

Figure 6. Schematic representation of the dysfunction in the reproductive axis of cultured fishes, and the exogenous hormonal interventions for the induction of oocyte maturation and spermiation.

Figure 7. Mean (SEM) volume of expressible milt over a 44-day period, from European sea bass $(n=8)$ administered different hormonal treatments of GnRHa, including GnRHa fastrelease systems (injection, I and EVAc implants), GnRHa slow-release systems (microspheres, $\mathrm{MC}$ and EVSL implants) and untreated controls. Asterisks indicate significant $(\mathrm{P} \leq 0.05)$ differences from the control group, for each sampling point. (Modified from from Sorbera et al., 1996).

Figure 8. Batch fecundity (x1000 eggs female) and fertilization success (Viability, \%) of an individual greater amberjack (weight $23.5 \mathrm{Kg}$ ) after treatment with GnRHa-loaded implants (50 
Broodstock management and hormonal manipulations of fish reproduction

$1938 \mu \mathrm{g} \mathrm{Kg}^{-1}$, arrows) at two times during the reproductive season. The female was maintained with two males of similar size $(23.5$ and $36.0 \mathrm{Kg})$, in a $40-\mathrm{m}^{3}$ square concrete tank, supplied with 1940 surface water $\left(22-24^{\circ} \mathrm{C}\right)$. 
The reproductive axis in fish

Environment

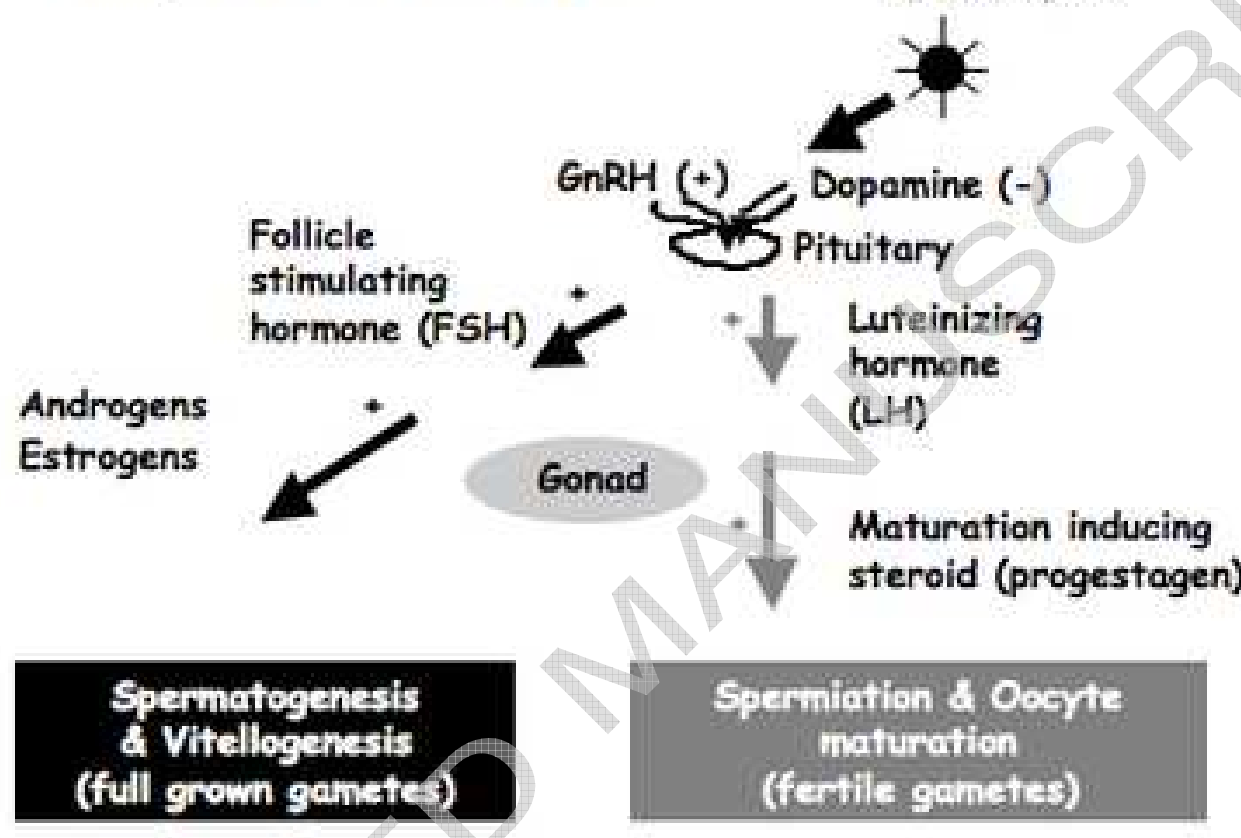

Mylonas, Fostier and Zanuy

Fig. 1 


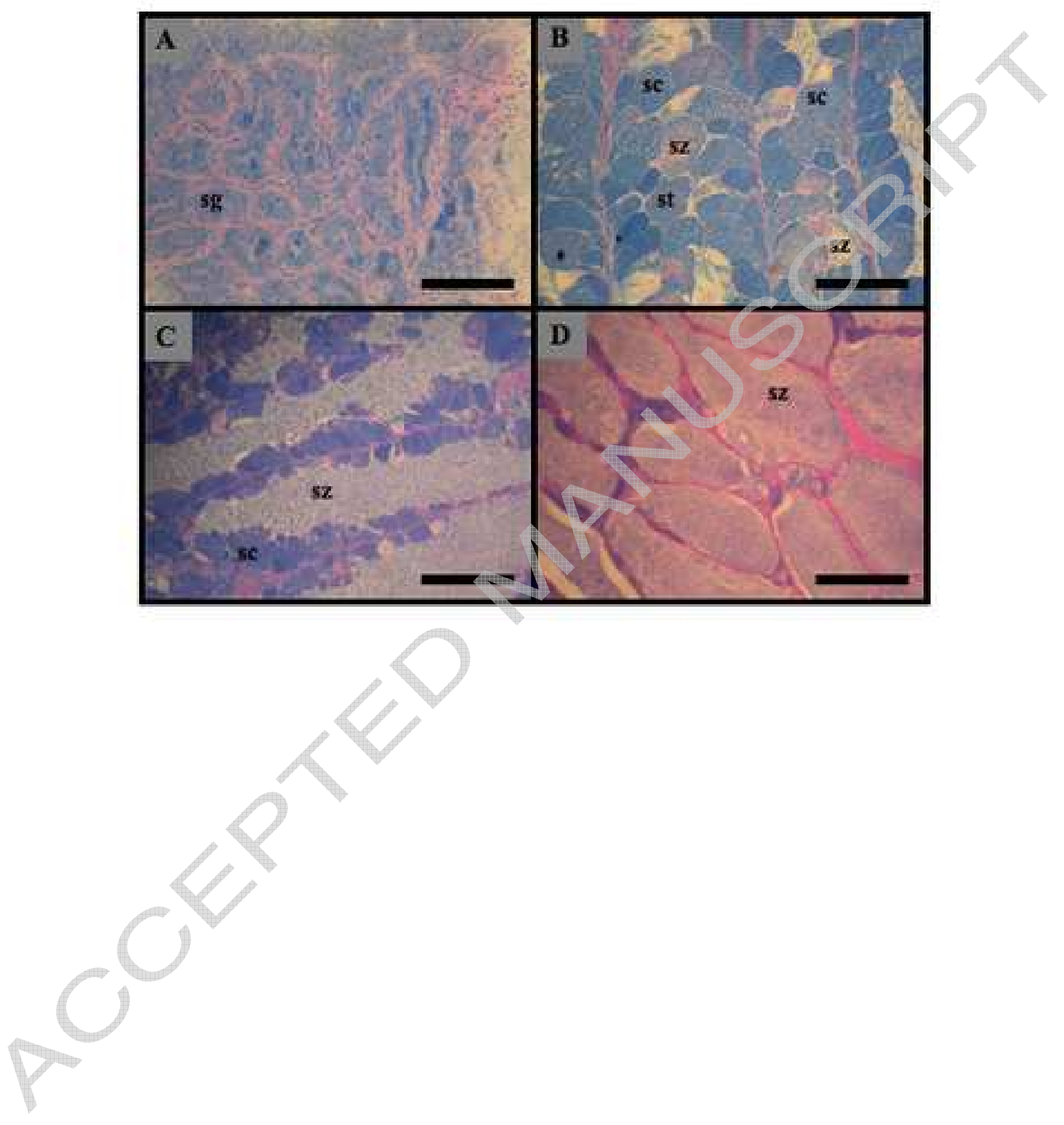

Mylonas, Fostier and Zanuy

Fig. 2 

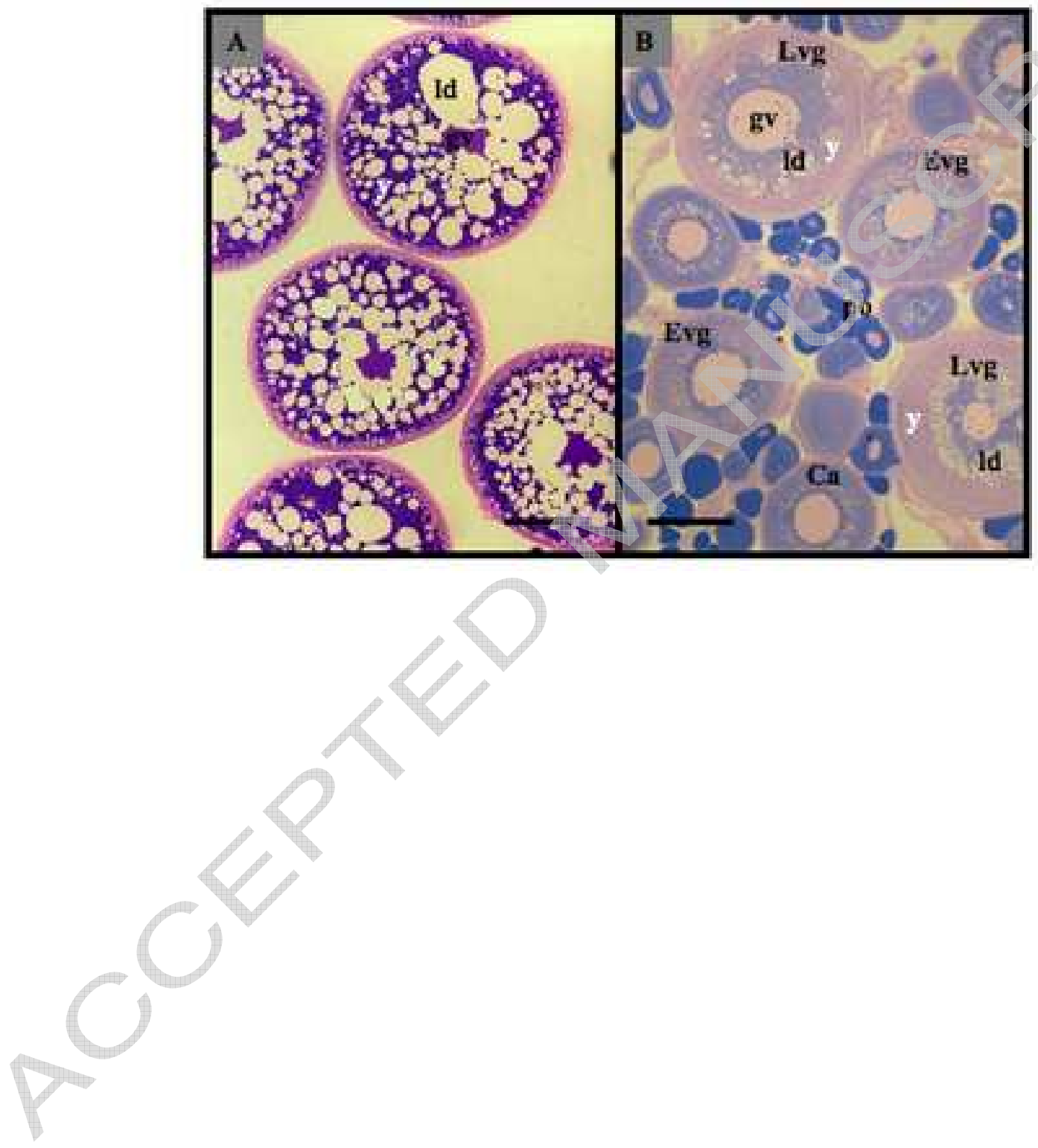

Mylonas, Fostier and Zanuy

Fig. 3 
A
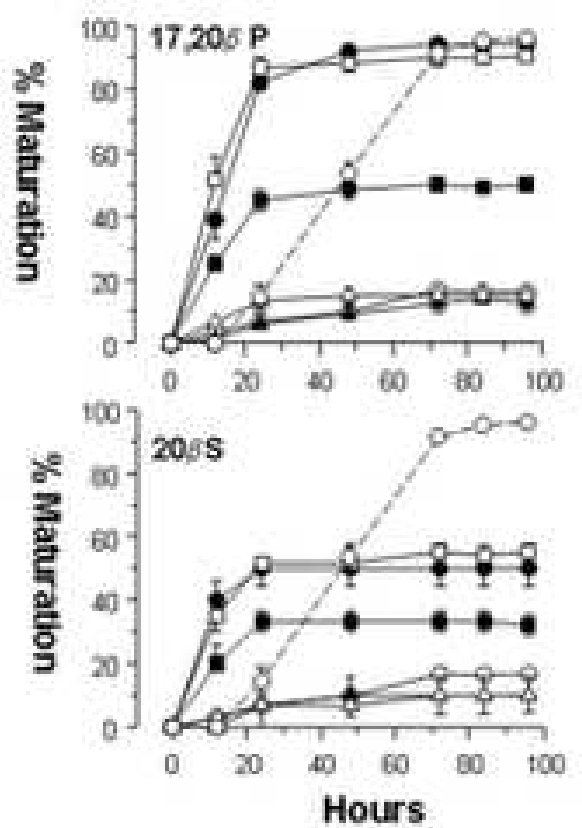

B
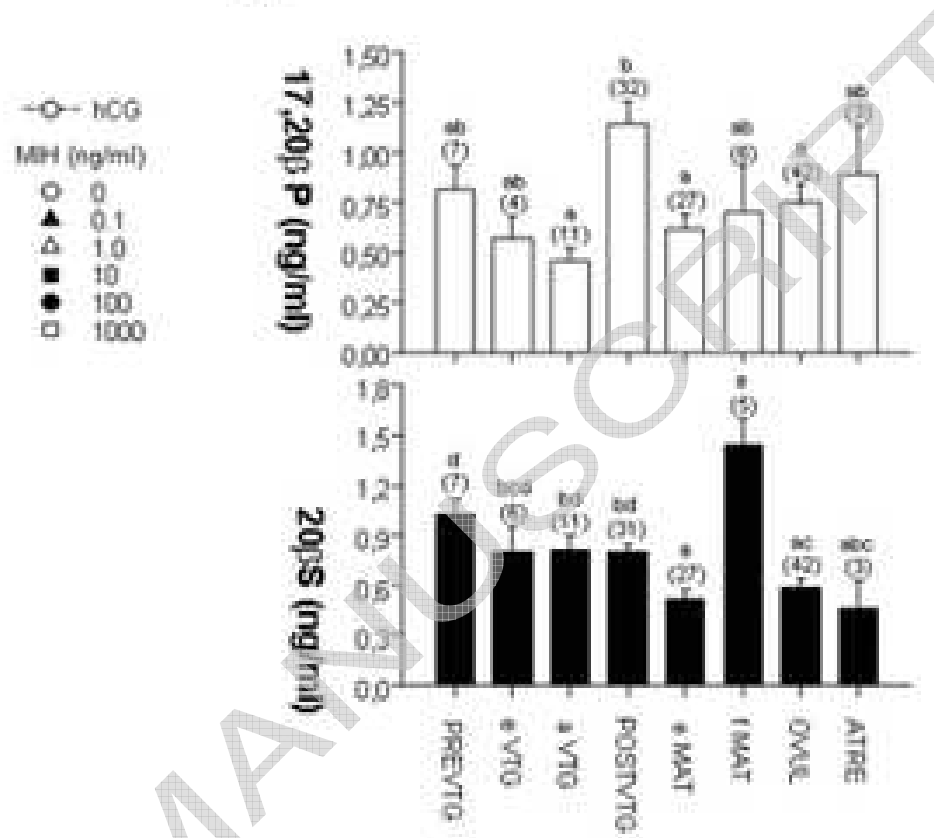
Oocyte stage of development

Mylonas, Fostier and Zanuy

Fig. 4 


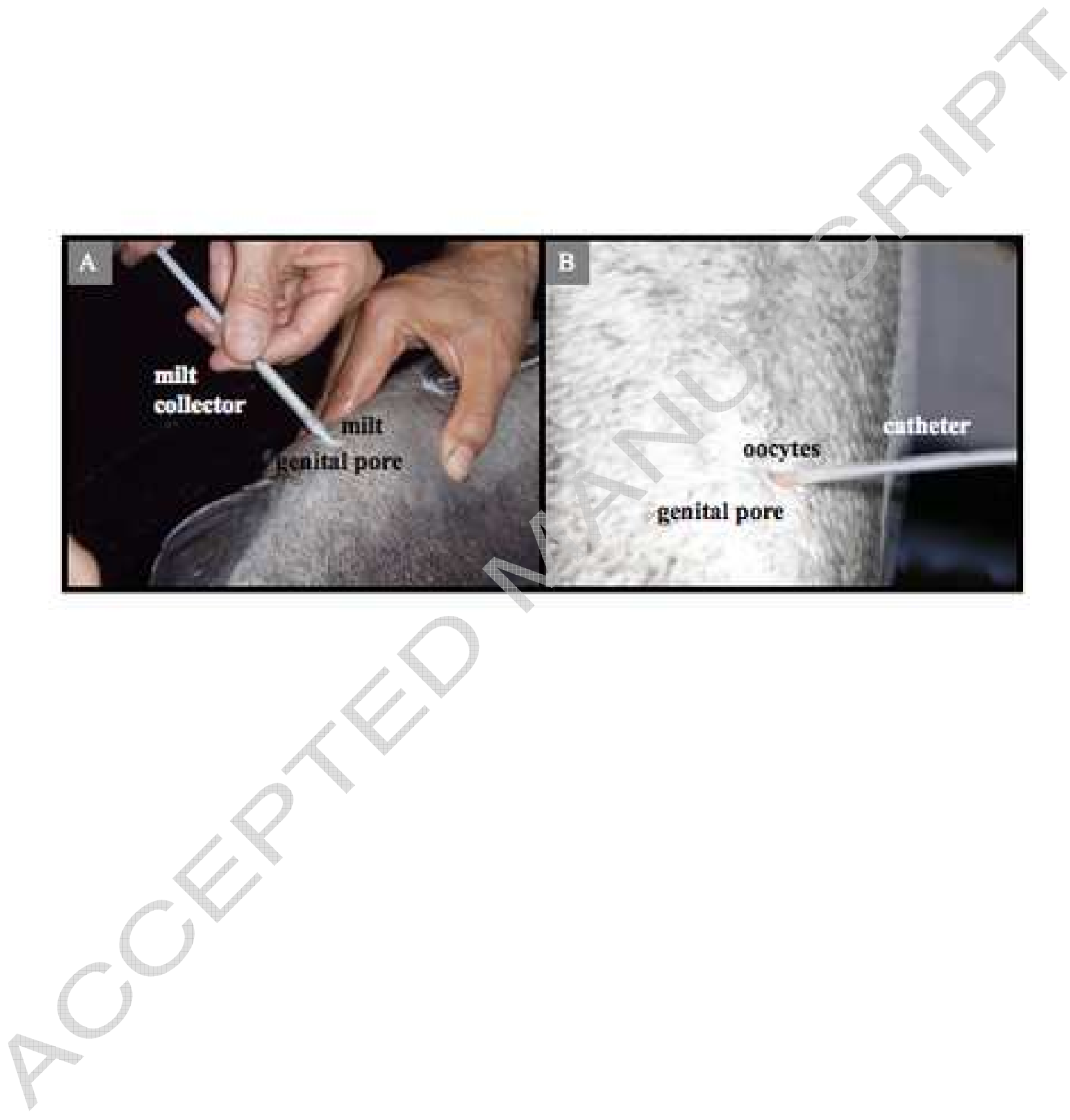

Mylonas, Fostier and Zanuy

Fig. 5 
Hermonal induction of oocyte maturation \& spermiation

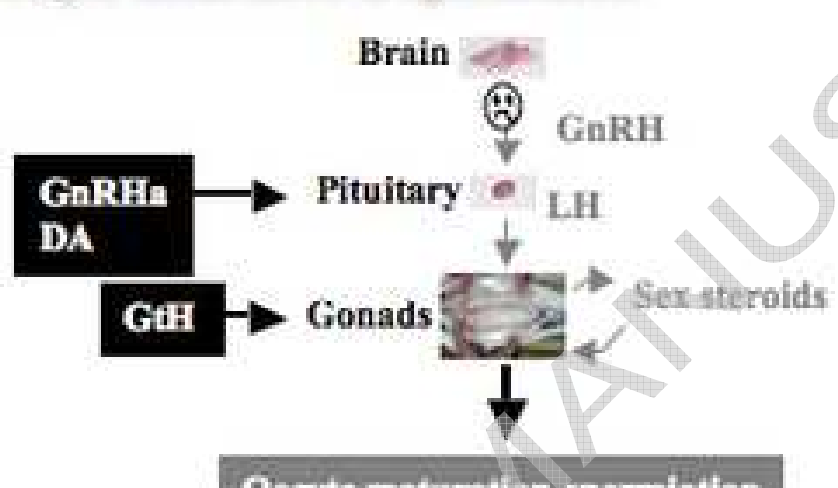

Oocyte maturation-spermintion

Mylonas, Fostier and Zanuy

Fig. 6 


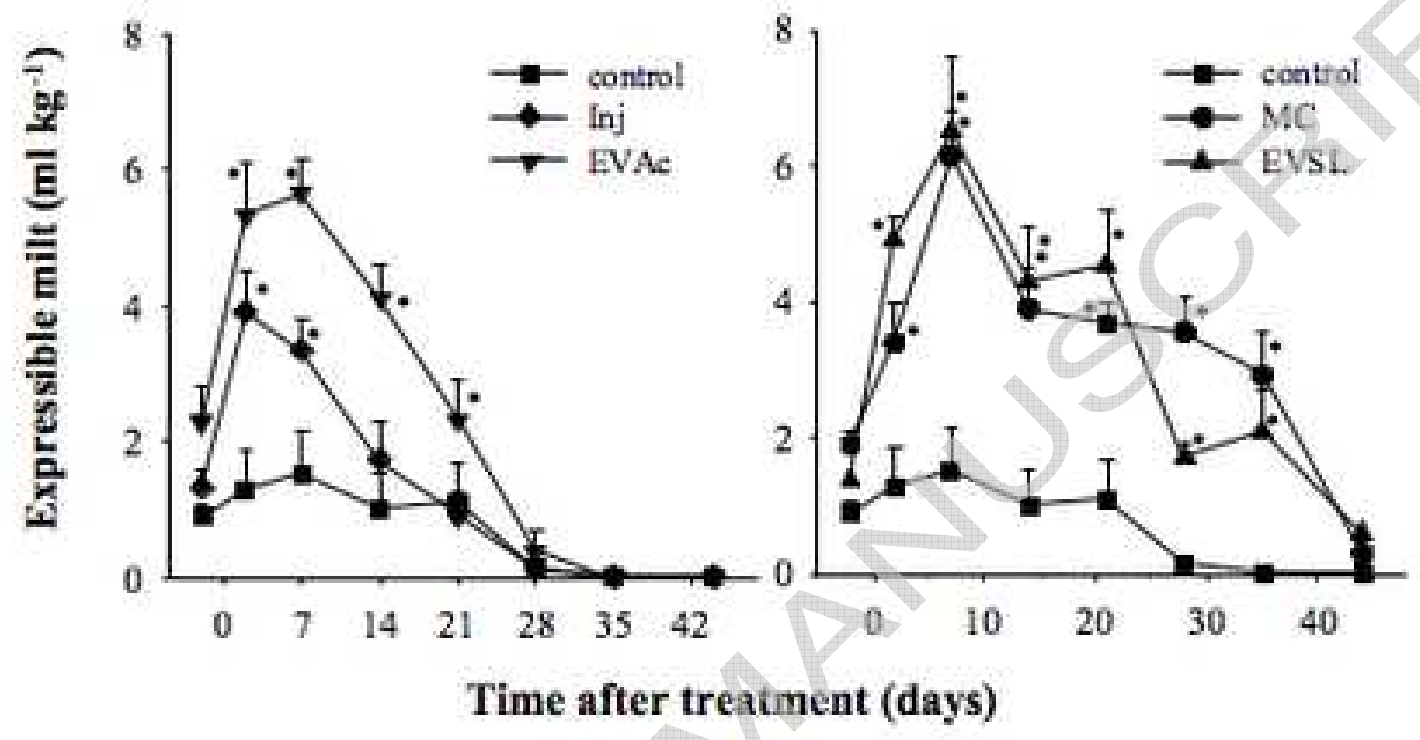

Mylonas, Fostier and Zanuy

Fig. 7 


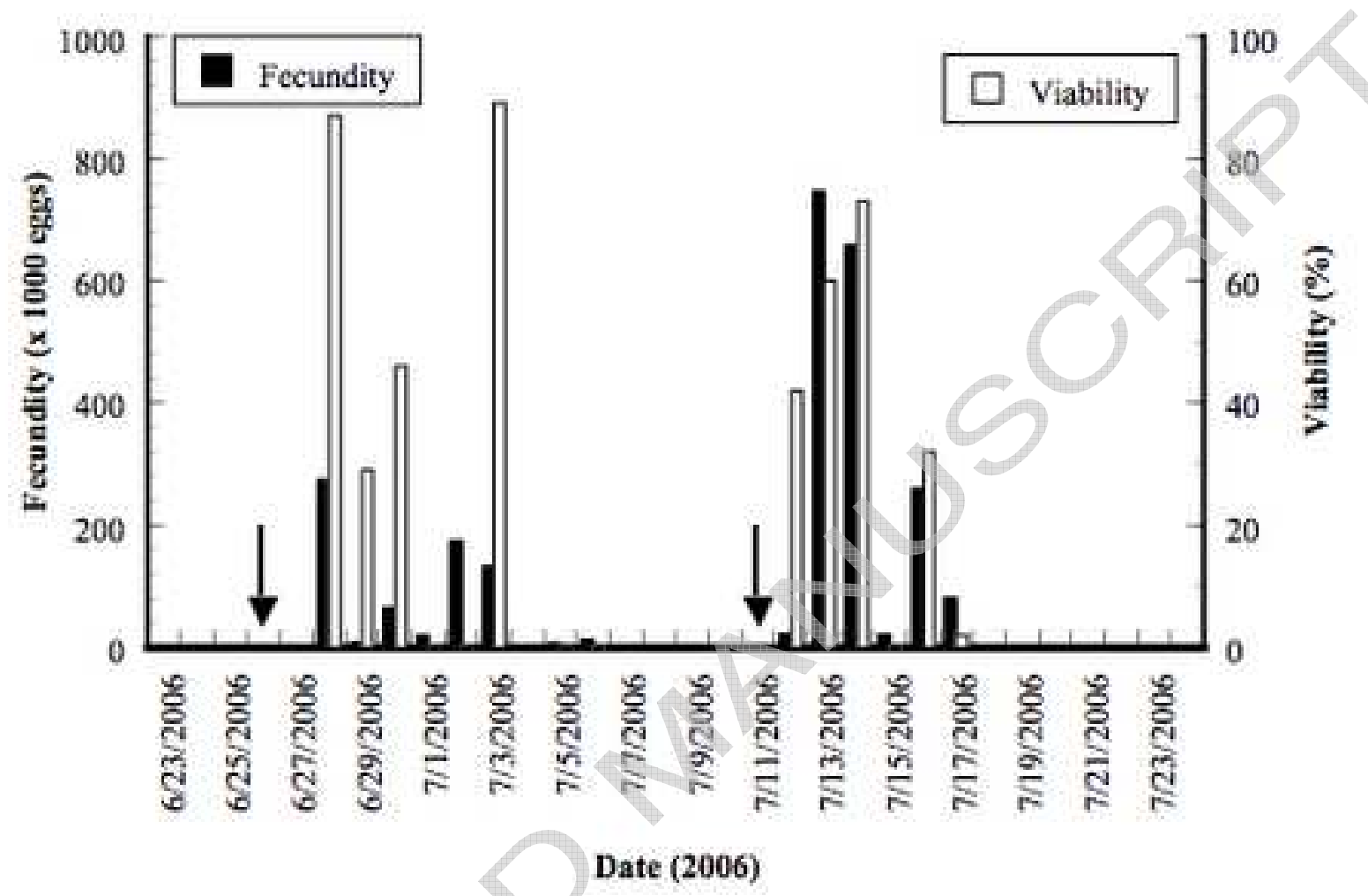

Mylonas, Fostier and Zanuy

Fig. 8 